\title{
Macht und Ohnmacht. Die Repräsentation ptolemäischer Königinnen in ägyptischen Tempeln*
}

\author{
Martina Minas (Trier)
}

Der ägyptische Pharao war, bis auf wenige Ausnahmen, stets männlich. Es waren Könige, die im Alten Ägypten wie in der Ptolemäerzeit offiziell die Macht ausübten. Zu allen Zeiten standen Königinnen neben ihnen, denn nach ägyptischem Weltverständnis gehörte zum Königtum nicht nur ein König, sondern auch eine Königin, entsprechend dem dualistischen Konzept, das die gesamte ägyptische Schöpfung durchdringt. Nur in den seltensten Fällen konnten Königinnen über ihre Aufgabe als Königsgemahlin hinauswachsen und die Machtposition eines Pharaos einnehmen, also 'König' werden wie Hatschepsut in der 18. Dynastie.

Mit diesem Beitrag werden die Machtverhältnisse innerhalb der ptolemäischen Dynastie anhand von Darstellungen der Königinnen in ägyptischen Tempeln und auf königlichen Stelen, die in pharaonischer Tradition stehen, verfolgt. Dabei gehe ich den Fragen auf den Grund, inwieweit die indigenen Tempelreliefs diese Traditionen widerspiegeln und inwiefern man auf altägyptische Vorbilder zurückgriff. Aus diesem Grund wird zuerst exemplarisch dargestellt, auf welche Weise altägyptische Königinnen in die Tempeldekoration integriert waren und welchen Stellenwert sie dabei einnahmen. Im Hauptteil werden die einzelnen Ptolemäerinnen chronologisch anhand beispielhafter Tempelszenen besprochen, bevor im Resümee zusammenfaßt wird, wie die oft ungewöhnlichen ptolemäischen Herrschaftsverhältnisse in die ägyptische Darstellungswelt übertragen und inwieweit altägyptische Vorgaben modifiziert wurden, um den neuen dynastischen Gegebenheiten angepaßt zu werden. Die ptolemäische Rundplastik kann dabei kaum als Vergleichsmaterial dienen, da die ikonographische Wiedergabe von ptolemäischen Frauen im Flachbild und diejenige in der Freiplastik teils deutlich voneinander abweichen. ${ }^{1}$ Die inzwischen zu den rundplastischen Bildnissen zahlreich

* Der vorliegende Artikel ist die erweiterte Fassung meines Vortrages anläßlich des Habilitationskolloquiums am 9. Juni 2004 vor dem Fachbereich III der Universität Trier. Ich danke Heinz Heinen für die kritische Durchsicht des Manuskriptes und hilfreichen Hinweise, Andrea Binsfeld, Bärbel Kramer und Joachim Hupe für ihre stetige Diskussionsbereitschaft. Die abgekürzt zitierte Literatur ist in der Bibliographie aufgeschlüsselt.

${ }^{1}$ So auch Albersmeier, Untersuchungen zu den Frauenstatuen, 61. 
erschienene Literatur wurde daher nur im Einzelfall für die vorliegende Studie der Tempelreliefs und Stelen herangezogen.

Die einzigen grundlegenden Vorarbeiten wurden 1978 von J. Quaegebeur publiziert. $^{2}$ Als Spezialist für Arsinoe II., der er mehrere Artikel gewidmet hat, ${ }^{3}$ konzentrierte er sich darin auf die frühen Ptolemäerinnen bis einschließlich Arsinoe III., die Schwestergemahlin Ptolemaios' IV. Philopator. Gerade aber die späten Ptolemäerinnen wurden politisch bestimmender und in den Tempeln ikonographisch zunehmend präsenter, besonders Kleopatra II. und III. Sie werden neben Kleopatra VII. im Zentrum dieser Untersuchung stehen.

Wie abhängig das Bild ptolemäischer Frauen von neuen Entdeckungen ist, zeigt der Papyrusfund mit griechischen Epigrammen, die Poseidipp von Pella verfaßt hat. ${ }^{4}$ Sie haben maßgeblich M. Pfrommers Studie zu Arsinoe II., Berenike II. und Arsinoe III. beeinflußt. ${ }^{5}$ Poseidipp zeigt die makedonischen Traditionen der Dynastie auf, womit ein Ausgleichsgewicht zu den ägyptischen geschaffen wird. So tritt das Doppelgesicht des ptolemäischen Herrscherhauses deutlich hervor, das auch in einer Untersuchung im rein indigenen Kontext nicht ignoriert werden darf.

R.A. Hazzard betont die Entwicklungen und den Wandel der ptolemäischen Monarchie zwischen 323 und 30 v.Chr., "for it started as a military monarchy headed by a king and ended as a civilian monarchy headed by a queen. ... the change was due to a change in the political imagination, one that germinated under Ptolemy II, grew under Kleopatra I, matured under Kleopatras II and III, and flowered under Kleopatra VII ... ". 6 Ob und in welchem Maße auch die traditionell geprägten ägyptischen Tempel diesen Wandel in der Monarchie in der späten Ptolemäerzeit mitmachten, soll hier aufgezeigt werden.

\section{Altägyptische Traditionen}

Als Alexander d. Gr. 332 v. Chr. Ägypten einnahm, zeigte er große Achtung vor den ägyptischen Kulten. Die Dynastie der Ptolemäer hat in der Folgezeit die ägyptischen Tempel durch Stiftungen und erhebliche Baumaßnahmen weiter gefördert. Sie erkannten, daß das Land mit jahrtausendealten Traditionen kaum gegen den Willen der ägyptischen Priesterschaften und mächtigen Tempelorganisationen regierbar war. Beide, ägyptischer Klerus und ptolemäische Fremdherrscher, waren auf die gegenseitige Unterstützung angewiesen. Somit traten die Ptolemäer die Nachfolge der ägyptischen Pharaonen an und wurden in den Tempel und den Kultvollzug integriert, zumindest nominell. anciens.

${ }^{2}$ Quaegebeur, Reines ptolémaïques.

3 Quaegebeur, BIFAO 69, 1971; JNES 30, 1971: GM 87, 1985. Id., Documents égyptiens

${ }^{4}$ G. Bastianini \& C. Gallazzi, Posidippo di Pella. Epigrammi (P.Mil. Vogl. VIII 309), Milano 2001. C. Austin \& G. Bastianini, Posidippi Pellaei quae supersunt omnia, Milano 2002.

5 M. Pfrommer, Königinnen vom Nil, Mainz 2002.

6 R.A. Hazzard, Imagination of a Monarchy: Studies in Ptolemaic Propaganda, Phoenix Suppl. Vol. 37, Toronto 2000, 156. 
Die Darstellungen des Pharaos beim Opfer und die damit implizierten rituellen Handlungen waren essentiell für die Aufrechterhaltung der Maat, der Weltordnung, und somit für das Wohlergehen Ägyptens. Die Wände ptolemäischer Tempel sind zu rund $80 \%$ von Ritualszenen bedeckt. ${ }^{7}$ Hier stehen sich Götter und Herrscher gegenüber, wobei der König ein Opfer überreicht und nach dem Prinzip 'do, ut des' eine ideelle Gegengabe von den Göttern erhält, wie die Herrschaft über Ägypten und ein langes Leben. Der altägyptische wie ptolemäische König wird in einigen Szenen von einer Königin begleitet, die dabei meist keine spezifischen Handlungen vornimmt, sondern in der Regel passiv bleibt und nur Sistrum, Blüten oder ein Lebenszeichen trägt. ${ }^{8}$ Wenn der altägyptische König von einem weiblichen Mitglied des Königshauses begleitet wird, ist dies in der Regel die große Königsgemahlin (hm.t nśwt wr.t) ${ }^{9}$

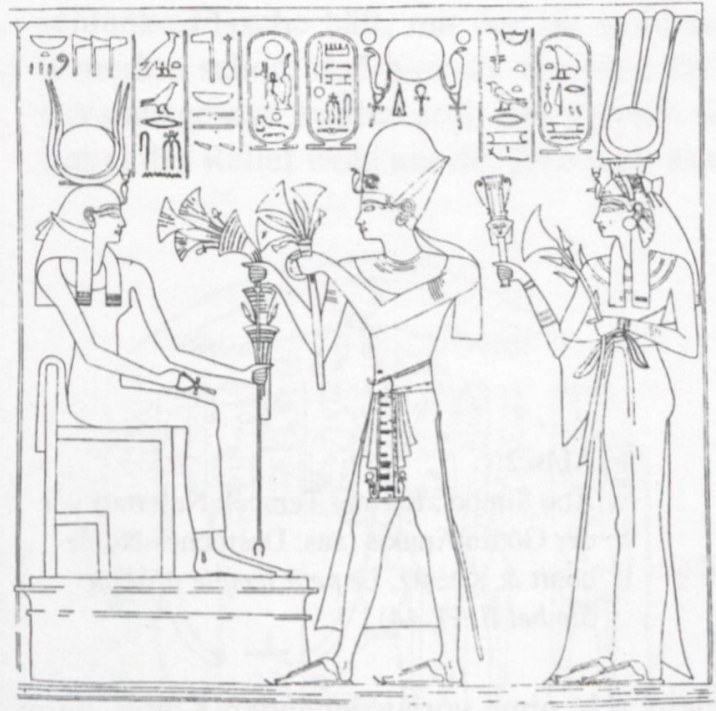
Abb. 1
Abu Simbel, Kleiner Tempel:
Ramses II. und Nefertari vor der Göttin Taweret (aus: Desroches- Noblecourt \& Kuentz, Le petit temple d'Abou Simbel II, Pl. 109).

Abb. 1 zeigt Ramses II. und seine große Königsgemahlin Nefertari aus der 19.
Dyn., wie sie vor der Göttin Taweret im kleinen Tempel von Abu Simbel opfern.

${ }^{7}$ Chr. Leitz, Der ägyptische Tempel und die ptolemäische Hieroglyphenschrift - ein Medium ganz besonderer Art, in: Medien in der Antike. Kommunikative Qualität und normative Wirkung, Vortragsreihe des Lehr- und Forschungszentrums für die Antiken Kulturen des Mittelmeerraumes am Archäologischen Institut der Universität zu Köln im Wintersemester 2002/03 (ed. H. von Hesberg), Köln 2003, 69.

${ }^{8}$ Robins, Wepwawet 1986, 10. Hölbl, Weiblicher Pharao, 89. In Karnak opfert Tiaa, Ehefrau Amenophis' II., hinter dem König jedoch eine spezifische Opfergabe, nämlich Wein, während Amenophis II. Weihrauch darbringt (P. Barguet \& J. Leclant, Karnak-Nord IV/2 (1949-1951), FIFAO 25/2, 1954, Pl. 50f.).

${ }^{9}$ Zum Prototyp einer altägyptischen Königin s. Troy, Patterns of Queenship. Robins, Women. Zur Rolle der Königin in der Außenpolitik und ihrer Darstellung beim Erschlagen der Feinde s. S. Roth, Gebieterin aller Länder. Die Rolle der königlichen Frauen in der fiktiven und realen Außenpolitik des ägyptischen Neuen Reiches, OBO 185, 2002, bes. 23-42. 
Nefertari trägt die für eine Königin des Neuen Reiches typischen Insignien: Über der Geierhaube mit königlichem Stirnuräus und dem stilisierten Uräenkranz ist eine hohe Doppelfederkrone angebracht, zusätzlich ein Kuhgehörn und eine Sonnenscheibe wie bei der Krone der Göttin Hathor. ${ }^{10}$

Hathor galt als der weibliche Prototyp der Schöpfung. Die Königin als Manifestation des urweiblichen Elements ergänzte so den König und stand damit in direkter Verbindung zu Hathor und deren Ikonographie. ${ }^{11}$ Die aus dem Götterkontext stammenden Insignien der Königin zeigen, daß neben dem göttlichen Königtum auch das Amt der Königin göttliche Züge aufweist, die bis auf das Alte Reich zurückgehen. Mythologisch so verankert, ist auch die Königin befähigt, Opferhandlungen zu vollziehen, weswegen sie den König begleiten kann.

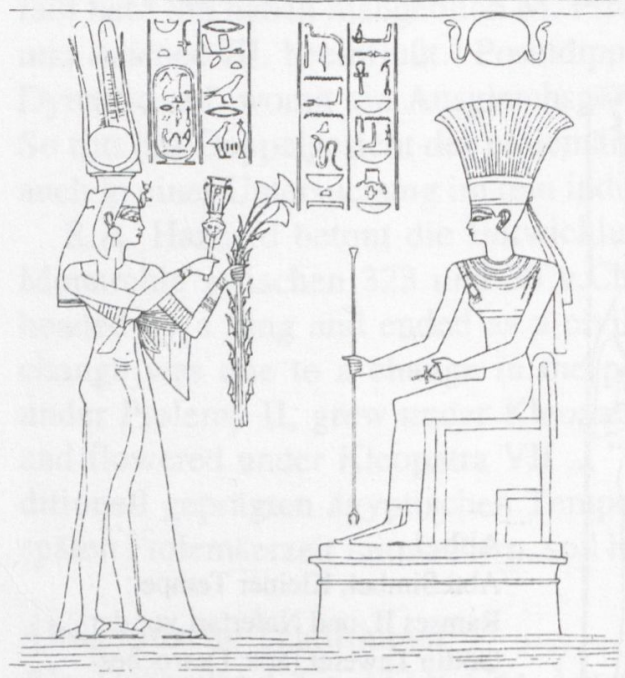
Abb. 2
Abu Simbel, Kleiner Tempel: Nefertari vor der Göttin Anukis (aus: Desroches-Noble- court \& Kuentz, Le petit temple d'Abou Simbel II, Pl. 44).

Nur im Einzelfall sind Königinnen allein, d.h. ohne vorausgehenden König, beim Opfer dargestellt. Dabei handelt es sich meist um so außergewöhnliche Köni-

${ }^{10}$ M. Malaise, Histoire et signification de la coiffure hathorique à plumes, $S A K 4$, 1976, 215 236. S. zur Federkrone bei Göttern: D. Budde, "Die den Himmel durchsticht und sich mit den Sternen vereint”. Zur Bedeutung und Funktion der Doppelfederkrone in der Götterikonographie, SAK 30, 2002, 57-102. Bei den Federn handelt es sich nach Robins, Wepwawet, 11-13, nicht um Straußenfedern wie bei Hathor, sondern um Doppelfalkenfedern, nach Albersmeier, Untersuchungen zu den Frauenstatuen, 54, um Straußen- od. Falkenfedern. Zu Uräus, Uräenkranz und Geierhaube s. Albersmeier, 40-42, 52-55.

11 Troy, Patterns of Queenship, 3; 53ff.: Hathor wird als Mutter und Ehefrau mit dem König assoziiert. Die Königsgemahlin mit Hathor-Krone ist in ihrer göttlichen Rolle auch die Mutter des (nächsten) Königs. Sie ist das Medium zur Erneuerung. Dies entspricht in gewisser Weise der Kamutef-Konzeption, nach der jeder König die Inkarnation seines Vorgängers ist. Es ist auf abstrakte Weise die Formulierung eines Begriffes der Unsterblichkeit, s. H. Jacobsohn, Die dogmatische Stellung des Königs in der Theologie der Alten Ägypter, AFO 8, 1939. K.-J. Seyfried, Generationeneinbindung, in: Thebanische Beamtennekropolen. Neue Perspektiven archäologischer Forschung. Internationales Symposion Heidelberg, 09.-13.06.1993, SAGA 12, 1995, 219-231. 
ginnen wie Nofretete und Nefertari. Abb. 2 zeigt eine weitere Szene aus dem kleinen Tempel von Abu Simbel, in der Nefertari ohne Königsbegleitung der Göttin Anukis mit Sistrum und Blumen huldigt, wieder mit der typischen Königinnenkrone ausgestattet. ${ }^{12}$ Hier trägt sie die Titel $r p^{c} . t$ wr.t h hs.w hm.t 'Fürstin, groß an Gunst, Gemahlin'. Szenen, die die Königin allein zeigen, sind stets im direkten Umfeld durch solche ergänzt, die den König beim Opfer zeigen, so daß seine Präsenz allgegenwärtig ist.

Neben der Königsgemahlin nimmt auch die Königsmutter eine herausragende Stellung ein und kann mit dem Pharao dargestellt sein. ${ }^{13}$ Dies ist bereits für die 6 . Dyn. überliefert, denn Pepi I. erscheint auf einer Königsstele aus Koptos mit seiner Mutter Iput vor dem Gott Min. ${ }^{14}$ In der 19. Dyn. wird Ramses II. in einem Relief, das aus Memphis stammen könnte und sich heute in Wien befindet, von seiner Mutter Tuja begleitet, die nicht nur passiv ein Sistrum, sondern auch eine schlanke Flasche hält, mit der sie wohl ein Libationsopfer vollzieht. ${ }^{15}$ Radwan bemerkte schon, daß hier die Stellung der Mutter hervorgehoben ist und nicht etwa ausgesagt werden soll, daß Ramses II. damals unverheiratet gewesen ist, ${ }^{16}$ zumal das Relief wohl aus der Zeit nach Ramses' 40. Regierungsjahr stammt.

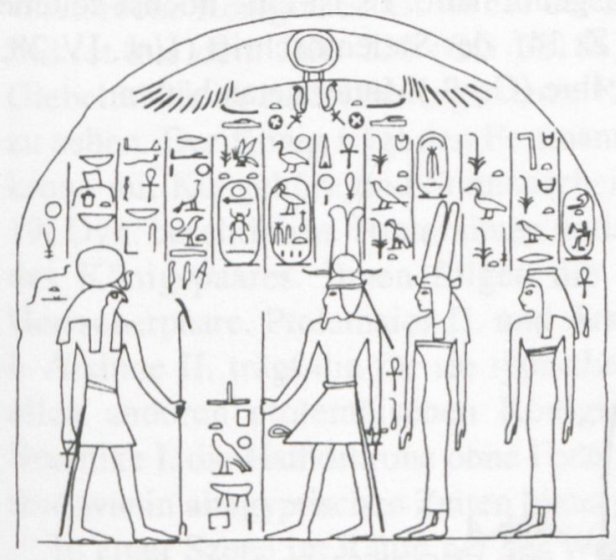

Abb. 3

Stele Berlin Inv. Nr. 15699:

Thutmosis II., Ahmes und Hatschepsut vor Re-Harachte (aus: Troy, Patterns of Queenship, 110, fig. 74).

12 Nefertari wird im kleinen Tempel von Abu Simbel explizit als Inkarnation der Göttin Hathor bezeichnet: Hölbl, Weiblicher Pharao, 89. S. auch R. Gundlach, Das Dekorationsprogramm der Tempel von Abu Simbel und ihre kultische und königsideologische Funktion, in: 3. Ägyptologische Tempeltagung: Systeme und Programme der ägyptischen Tempeldekoration, Hamburg, 1.-5. Juni 1994 (ed. D. Kurth), ÄAT 33, 1995, 57-60.

13 Zur Bedeutung der Königsmütter im Alten und Mittleren Reich s. S. Roth, Die Königsmütter des Alten Ägypten von der Frühzeit bis zum Ende der 12. Dynastie, ÄAT 46, 2001.

14 A. Radwan, Die Darstellungen des regierenden Königs und seiner Familienangehörigen in den Privatgräbern der 18. Dynastie, MÄS 21, 1968, 92 mit Anm. 79 (mit weiterer Literatur).

15 Wien, KHM ÄS 5091: A. Radwan, Ramses II. und seine Mutter vor Osiris, SAK 6, 1978, 157-161. S. auch Ch. Ziegler, The Pharaohs, London 2002, 152, 422 (Nr. 89).

${ }^{16}$ A. Radwan, SAK 6, 1978, 160. 
Unter Berücksichtigung dynastischer Belange konnten auch zwei Königinnen dargestellt werden. So stehen auf einer Stele aus der 18. Dyn., die sich in Berlin befindet, ${ }^{17}$ hinter Thutmosis II. die Königsmutter Ahmes und die große Königsgemahlin Hatschepsut (Abb. 3). Ahmes' ursprünglicher Titel lautete śn.t nśwt 'Königsschwester', der in $m w$.t nśwt 'Königsmutter' umgewandelt worden ist. Ahmes war die Tochter des Königs Ahmose und der Königin Ahmes-Nefertari sowie große Königsgemahlin Thutmosis' I., des Vaters Thutmosis' II. Sie war nicht die Mutter Thutmosis' II., sondern seine Stief- und Schwiegermutter, denn Hatschepsut ist ihre Tochter. Gleichzeitig war sie die Schwester des für die 18. Dyn. so wichtigen Königs Amenophis I. ${ }^{18}$

Bereits verstorbene altägyptische Königinnen konnten in Ausnahmefällen auch auf der göttlichen Seite einer Reliefszene abgebildet werden und ein Opfer durch den lebenden König erhalten. Bekanntestes Beispiel ist der Denkstein des Königs Ahmose vom Beginn der 18. Dyn. (CG 34002), ${ }^{19}$ der den König in beiden Giebelszenen vor seiner Großmutter Tetisheri im Opfergestus zeigt (Abb. 4). Tetisheri war nicht nur Königsgemahlin ( $h m . t$ nśwt), sondern auch Königsmutter ( $m w$.t nśwt), der als Verbindungsglied in der Legitimationskette der noch jungen 18. Dyn. höchste Bedeutung zukam, zumal sie für den unmündigen Ahmose, den Vater Amenophis' I., die Regentschaft ausgeübt hatte. Es ist eine höchst seltene Darstellung. So betont der König auch in Z. 14f. der Steleninschrift (Urk. IV 28, 14-15), daß ältere Könige dies niemals für ihre (Groß-)Mütter getan hätten.

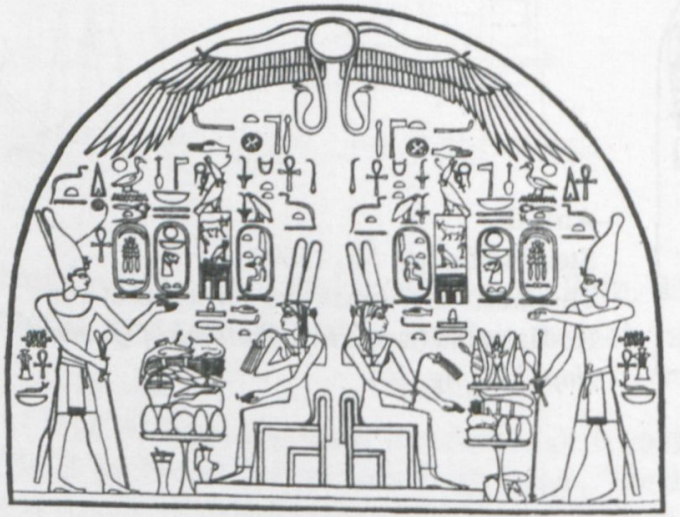

Abb. 4

Stele CGC 34002: Denkstein des Ahmose (aus: E.R. Ayrton, C.T Curelly \& A.E.P. Weigall, Abydos III, London [EEF] 1904, Pl. 52).

17 Inv. Nr. 15699: Wildung, Zwei Stelen aus Hatschepsuts Frühzeit, Festschrift zum 150jährigen Bestehen des Berliner Ägyptischen Museums, Staatliche Museen zu Berlin: Mitteilungen aus der ägyptischen Sammlung, Berlin 1974, 256f., Taf. 34a. Robins, Women, 43, Abb. 8. Troy, Patterns of Queenship, 110, Fig. 74.

18 Wildung, Zwei Stelen aus Hatschepsuts Frühzeit (Anm. 17), vermutet, daß die Veränderung ihres Titels zur Zeit der Alleinherrschaft der Hatschepsut vorgenommen worden ist, womit betont werden sollte, daß Ahmes die Mutter der Regentin war.

${ }^{19}$ Urk. IV 26-29. P. Beylage, Aufbau der königlichen Stelentexte vom Beginn der 18. Dynastie bis zur Amarnazeit, I: Transkription und Übersetzung der Texte (S. 1-9), II: Methodik und Analyse der Texte (S. 559-562), ÄAT 54, 2002 (mit weiterer Literatur). 
Die Königinnen des Neuen Reiches tragen seit Ahmes-Nefertari, der Mutter Amenophis' I., den Titel hm.t-ntr r 'Gottesgemahlin' des Amun. Das Amt der Gottesgemahlin, auf Theben beschränkt, wurde mit dem Tod der Anchnesneferibre, Tochter Psammetichs II. (26. Dyn.), nicht mehr besetzt, wohl als direkte Konsequenz der ersten persischen Besetzung. ${ }^{20}$ Die Gottesgemahlinnen, die die Götter direkt und ohne männliche Begleitung verehren konnten, trugen die Insignien einer Königin, einschließlich einer Doppelfederkrone, Hörner und Sonnenscheibe. ${ }^{21}$

Nach diesem kurzen Überblick zu den Darstellungsvarianten altägyptischer Königinnen in Tempelreliefs und auf königlichen Stelen folgt nun die Diskussion der ptolemäischen Königinnen. Hierbei werden die frühen Ptolemäerinnen bis Arsinoe III. nur summarisch betrachtet, da J. Quaegebeur (s.o.) sie schon eingehend besprochen hat.

\section{Berenike I.}

Aus der Zeit Ptolemaios' I. Soter sind nur sehr wenige Tempelreliefs erhalten. Seine Gemahlin Berenike I. ist in keinem der Reliefs zu finden, sondern nur in Ahnendarstellungen seit der Regierungszeit des dritten Ptolemäers, also als bereits verstorbene Königin. So ist sie auf der Stele von Kom el-Hisn, dem sog. KanoposDekret aus dem Jahr 238 (CG 22186), dargestellt:22 Auf der linken Seite des Giebelfeldes ist zuerst das regierende Königspaar Ptolemaios III. und Berenike II. zu sehen. Der König trägt den Festmantel, ${ }^{23}$ die Königin die typische hohe Federkrone mit Kuhgehörn und Sonnenscheibe, wie oben bereits für Nefertari aus der 19. Dyn. beschrieben. Hinter ihnen notieren Thot und Seschat die Regierungsjahre des Königspaares. Ihnen folgen die beiden vorangegangenen ptolemäischen Herrscherpaare, Ptolemaios II. und Arsinoe II. sowie Ptolemaios I. und Berenike I. Arsinoe II. trägt die für sie typische dreiteilige Kompositkrone, ${ }^{24}$ die sie von allen anderen ptolemäischen Königinnen rein ikonographisch unterscheidet, Berenike I. die Hathorkrone ohne Federn. Regierende wie verstorbene Königinnen sind wie in altägyptischen Zeiten hinter dem entsprechenden König dargestellt.

In einer Szene im Raum bei der Westtreppe im Tempel von Edfu opfert Ptolemaios IV. Philopator Speisen an Horus von Edfu, Hathor und Horsemataui sowie

${ }^{20}$ M. Ayad, Some Thoughts on the Disappearance of the Office of the God's Wife of Amun, Papers presented to Alan R. Schulman, The SSEA Journal 28, 2001, 1-14.

${ }_{21}^{21}$ Robins, Women, 156 und Abb. 45f.

22 Zur Stele von Kom el-Hisn s. Quaegebeur, Documents égyptiens anciens, 247 mit ill. C (weitere Literatur in Anm. 16). Soeben erschienen ist die neue Arbeit von Stefan Pfeiffer, Das Dekret von Kanopos (238 v.Chr.). Kommentar und historische Auswertung eines dreisprachigen Synodaldekretes der ägyptischen Priester zu Ehren Ptolemaios' III. und seiner Familie, APF Beiheft 18, 2004. Das Giebelfeld der Stele behandelt er auf S. 28-38.

${ }^{23}$ Zum Festmantel s. R. Bianchi, The Striding Draped Male Figure of Ptolemaic Egypt, in: Das ptolemäische Ägypten. Akten des Int. Symposions, 27,-29. September 1976 in Berlin (edd. H. Maehler \& V.M. Strocka), Mainz 1978, 95-102.

${ }^{24}$ Zur Kompositkrone Arsinoes II. s. Quaegebeur, GM 87 (1985), 73-78. Albersmeier \& Minas, Weihrelief, 14 (mit weiterer Literatur in Anm. 30). 
seinen königlichen Ahnen, dem dritten bis ersten Ptolemäerpaar, also Ptolemaios III. Euergetes und Berenike II., Ptolemaios II. und Arsinoe II., Ptolemaios I. und Berenike I. Berenike I. und II. tragen dabei die charakteristischen hohen Königinnenkronen, Arsinoe II. wieder die typische dreiteilige Kompositkrone. Bei dieser Szene ist eine interessante Verwechslung der Königinnennamen zu vermerken: Beim ersten Ptolemäerpaar ist fälschlicherweise Arsinoe anstatt Berenike (II.) in die Kartusche der Königin geschrieben worden. 25

\section{Arsinoe II.}

Arsinoe II., die Schwestergemahlin Ptolemaios' II., nahm eine Ausnahmestellung in der ptolemäischen Dynastie ein, die von Quaegebeur hervorragend beleuchtet worden ist (s. Anm. 3). Gegen Quaegebeurs Annahme ist bereits sie selbst, und nicht erst ihre Nachfolgerin Berenike II., als erste ptolemäische Königin mit dem regierenden König zu ihren Lebzeiten in Ritualszenen dargestellt worden, ${ }^{26}$ wie mit einer Szene auf dem Architrav eines Naos aus Athribis zu belegen ist. ${ }^{27}$ Arsinoe II. führt dabei kein spezifisches Opfer aus, sondern hält zwei Sistren in ihren Händen. Ebenfalls zu ihren Lebzeiten erhielt sie auch den Königstitel nśwtbitj, der sie als Koregentin auszeichnete. ${ }^{28}$ Nach ihrem Tod ließ Ptolemaios II. sie vergöttlichen und initiierte verschiedene Kulte für sie, im Zuge derer sie auch als Mitgöttin in den ägyptischen Tempeln verehrt wurde. ${ }^{29}$

Arsinoes göttlicher Status und ihre außergewöhnliche Stellung in der ptolemäischen Dynastie werden durch die Stelen deutlich, auf denen Ptolemaios II. seine verstorbene und vergöttlichte Schwestergemahlin anbetet. ${ }^{30}$ Letztendlich lassen sich diese Repräsentationen Arsinoes II. mit der oben angeführten Darstellung des Ahmose vor Tetisheri aus der 18. Dyn. vergleichen (Abb. 4). Solche Denksteine sind jedoch sowohl für das ptolemäische als auch das alte Ägypten exzeptionell.

\section{Berenike II. und Arsinoe III.}

Berenike II. und Arsinoe III., Gemahlinnen des dritten und vierten Ptolemäers, werden wie Arsinoe II. zu ihren Lebzeiten zusammen mit dem König in Ritualszenen dargestellt und postum mit den entsprechenden Königen als Ahnenpaar verehrt. 31

${ }^{25}$ Edfou IX, Pl. 36a; Edfou XV, Pl. 32f. (Photo). S. auch Quaegebeur, Reines ptolémaïques, 248 , ill. Winter, Herrscherkult, 152, Dok. 28.

26 Quaegebeur, Reines ptolémä̈ques, 254. Hölbl, Weiblicher Pharao, 91, wiederholte Quaegebeurs Annahme noch vor kurzem. $4.2)$.

27 Stockholm, Medelhavsmuseet Inv. 10026. Albersmeier \& Minas, Weihrelief, 7, 15 (Taf.

28 Quaegebeur, BIFAO 69. Id., JNES 30. Id., GM 97, 1985, 75f. Albersmeier \& Minas, Weihrelief, 6f. Hölbl, Weiblicher Pharao, 91, hingegen nimmt an, daß sie die Königstitulatur erst postum erhielt.

${ }^{29}$ Zusammenfassung bei Minas, Hieroglyphische Ahnenreihen, 93-96.

${ }^{30}$ Quaegebeur, BIFAO 69, 191-217. Id., JNES 30 (1971), 239-270.

31 Zu Details s. Quaegebeur, Reines ptolémaïques, 254f. Winter, Herrscherkult, 147-160. Hölbl, Weiblicher Pharao, 91f. 
Berenike II. ist zwar nicht die erste Königin, die zu Lebzeiten zusammen mit dem König dargestellt worden ist, doch begleitet sie erstmalig den ptolemäischen König bei Szenen der Herrschaftsübergabe. Die Darstellung auf dem Nordpfosten des Euergetes-Tores in Karnak, wo Chons Ptolemaios III. und Berenike II. die Herrschaft übergibt (Abb. 5), ist eines der bekanntesten Beispiele: ${ }^{32}$

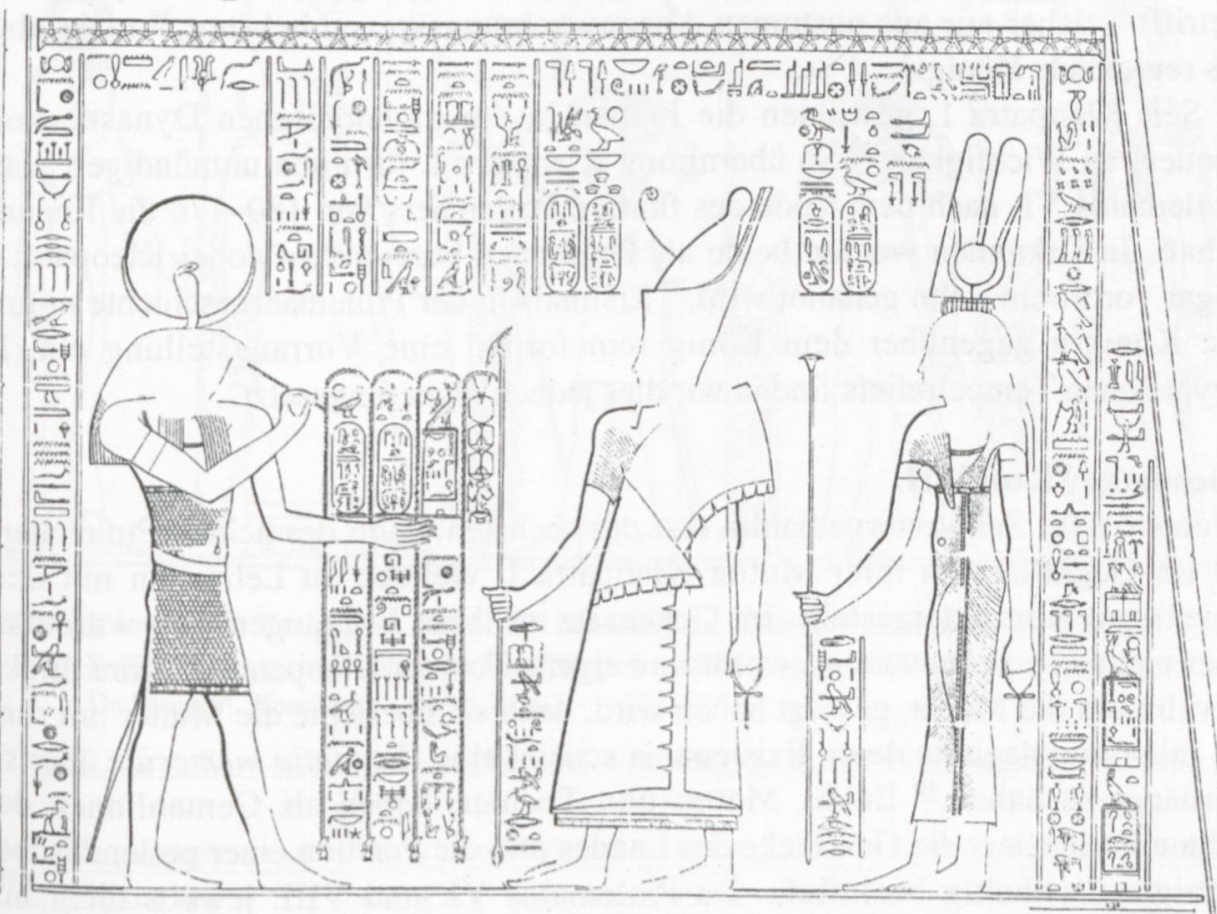

Abb. 5 Karnak, Euergetes-Tor, Nordpfosten: Chons übermittelt Ptolemaios III. Euergetes I. und Berenike II. die Regierungsjahre (aus: P. Clère, La porte d'Évergète à Karnak, 2 partie, MIFAO 84, Le Caire 1961, Pl. 43).

Berenike II. wird in der rechten Randzeile als weiblicher Horus bezeichnet und trägt damit als erste ptolemäische Königsgemahlin einen Horusnamen, nämlich Hr.t h.k3.t ir.t $n h k^{3}$.t 'Tochter eines Herrschers, die von einer Herrscherin geboren ist', womit fiktiv auf Arsinoe II. als Mutter Bezug genommen wird, ${ }^{33}$ wie auch in der offiziellen Filiation. Berenike II. wird so durch eine angebliche Erbfolge zusätzlich legitimiert, wodurch die eigene Stellung der Königin an Bedeutung gewinnt. Berenike trägt die typische Königinnenkrone, allerdings sind nun Sonnenscheibe und Kuhhörner in Relation zu den Federn deutlich kleiner als im Neuen Reich dargestellt.

32 P. Clère, La porte d'Évergète à Karnak, $2^{\mathrm{e}}$ partie, MIFAO 84, Le Caire 1961, Pl. 43. Quaegebeur, Reines ptolémaïques, 254, ill. K.

${ }^{33}$ So auch Hölbl, Weiblicher Pharao, 91, und Huß, Ägypten in hellenistischer Zeit, 354, der betont, daß sich Berenike II. aus Legitimitätsgründen eng an ihre dynastische Vorgängerin anschloß, vor allem über das geschaffene Mutter-Tochter-Verhältnis. 


\section{Kleopatra I.}

Die Herrschaft Ptolemaios' V. ist von einheimischen Aufständen geprägt, in deren Verlauf sich eine Gegendynastie in der Thebais etablieren konnte, so daß gerade in den großen Tempelanlagen Oberägyptens wenig in seiner Herrschaft dekoriert worden ist. ${ }^{34}$ Wie Berenike I. ist Kleopatra I. - was ägyptische Tempelreliefs betrifft - daher nur aus postumen Ahnenverehrungsszenen bekannt, ${ }^{35}$ nicht aber als regierende Königin.

Seit Kleopatra I. gewinnen die Frauen in der ptolemäischen Dynastie konsequent an Wichtigkeit. ${ }^{36}$ So übernimmt Kleopatra I. für ihren unmündigen Sohn Ptolemaios VI. nach dem Tode des fünften Ptolemäers von 180-176 die Regentschaft. In Urkunden werden beide als Pharaonen bezeichnet, wobei Kleopatra I. sogar vor ihrem Sohn genannt wird. ${ }^{37}$ Erstmals in der Ptolemäergeschichte nimmt die Königin gegenüber dem König rein formal eine Vorrangstellung ein. In ägyptischen Tempelreliefs finden wir dies jedoch nicht umgesetzt.

\section{Kleopatra II. und III.}

Kleopatra II., Schwestergemahlin erst des sechsten, dann des achten Ptolemäers, ist im Gegensatz zu ihrer Mutter Kleopatra I. vielfach zu Lebzeiten mit dem jeweiligen König dargestellt. Im Gegensatz zu ihren Vorgängerinnen wurde sie aber niemals postum verehrt, wofür ihre eigene Tochter Kleopatra III., ihre direkte Rivalin um die Macht, gesorgt haben wird, denn sie überlebte die Mutter um rund 15 Jahre und negierte deren Existenz, ja scheint eine damnatio memoriae über sie verhängt zu haben. ${ }^{38}$ Beide, Mutter und Tochter, haben als Gemahlinnen des achten Ptolemäers die Geschicke des Landes und die Position einer ptolemäischen Königin nachhaltig beeinflußt. Da Ptolemaios VI. und VIII. jeweils nicht nur lange regierten, sondern es unter ihrer Herrschaft auch zu weitreichenden Baumaßnahmen, ja zu einer Blütezeit des Tempelbaus kam, sind Kleopatra II. und III. entsprechend oft mit ihnen zusammen dargestellt.

Ptolemaios VI. regierte mit einer kurzen Unterbrechung von 180-145, seit 175 mit seiner Schwestergemahlin Kleopatra II. Wie gewohnt, wird die Königin in einigen Ritualszenen hinter ihrem Brudergemahl dargestellt. Abb. 6 zeigt das Ptolemäerpaar im inneren Vestibül des Sobek- und Haroeris-Tempels von Kom Ombo, wo ihnen die Herrschaft durch die Götter Chons, Haroeris und Sobek übermittelt wird: ${ }^{39}$

34 S. dazu E. Lanciers, Die ägyptischen Tempelbauten zur Zeit des Ptolemaios V. Epiphanes (204-180 v.Chr.), Teil 1, MDAIK 42, 1986, 81-98; Teil 2, MDAIK 43, 1987,173-182.

35 Winter, Herrscherkult, Dok. 8-10, 14, 18, 22.

36 S. dazu Hölbl, Geschichte, 185f. Hu3, Ägypten in hellenistischer Zeit, 538, 540. J. Whitehorne, Cleopatras, London 1994, $86 \mathrm{f}$.

37 Pestman, Chronologie, 46.

${ }^{38}$ Minas, Hieroglyphische Ahnenrethen, 155, 192. Huß, Ägypten in hellenistischer Zeit, 640.

${ }^{39}$ A. Gutbub (ed. D. Inconnu-Bocquillon), Kôm Ombo I. Les inscriptions du naos (sanctuaires, salle de l'ennéade, salle des offrandes, couloir mystérieux), IFAO 1995, 13-15, Nr. 14 


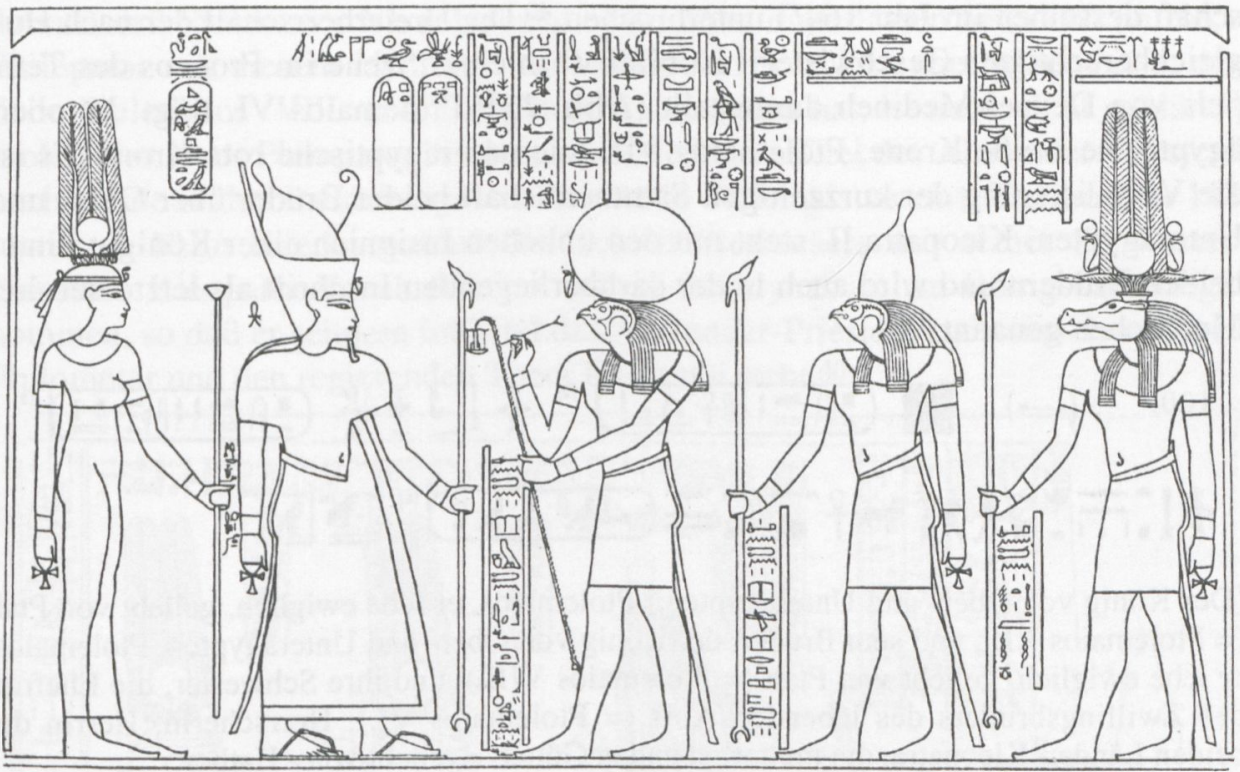

Abb. 6 Kom Ombo, Tempel des Sobek und des Haroeris, inneres Vestibül: Chons, Haroeris und Sobek übermitteln Ptolemaios VI. Philopator und Kleopatra II. die Regierungsjahre (aus: De Morgan, Kom Ombo II, Nr. 810).

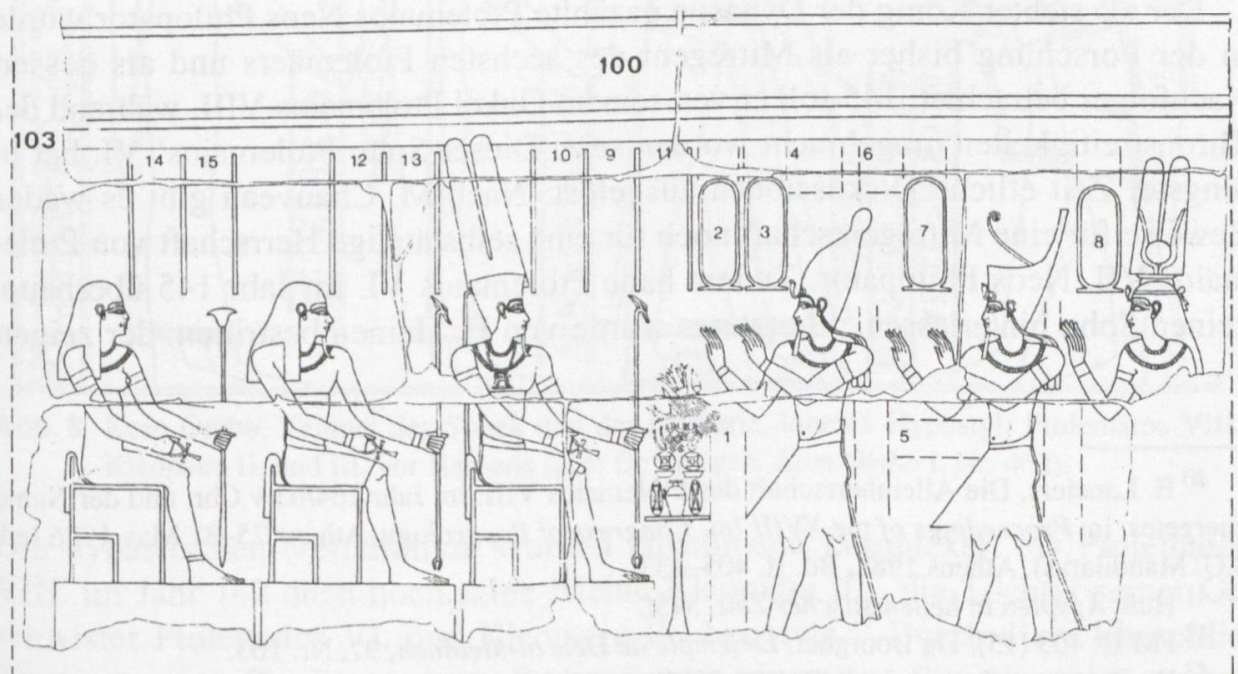

Abb. 7 Deir el-Medineh, Tempel der Hathor, Pronaos: Ptolemaios VI. und VIII. sowie Kleopatra II. vor Amun-Re, Amun und Amaunet (aus: Du Bourguet, Le temple de Deir al-Médîneh, 97, Nr. 103).

Die Herrschaft beider wurde von der Dreierherrschaft mit ihrem gemeinsamen Bruder Ptolemaios VIII. von 170-164/3 und einer kurzen Phase der Alleinherr- 
schaft desselben im Jahr 164/3 unterbrochen. ${ }^{40}$ Die Dreierherrschaft der nach Huß gleichberechtigten Geschwister ${ }^{41}$ ist bildhaft in einer Szene im Pronaos des Tempels von Deir el-Medineh dargestellt (Abb. 7) ${ }^{42}$ Ptolemaios VI. trägt die oberägyptische weiße Krone, Ptolemaios VIII. die unterägyptische rote Krone. Es ist die Visualisierung der kurzzeitigen Samtherrschaft beider Brüder über Ober- und Unterägypten. Kleopatra II. steht mit den üblichen Insignien einer Königin hinter beiden Brüdern und wird auch in der darüberliegenden Inschrift als letzte der drei Monarchen genannt: ${ }^{43}$

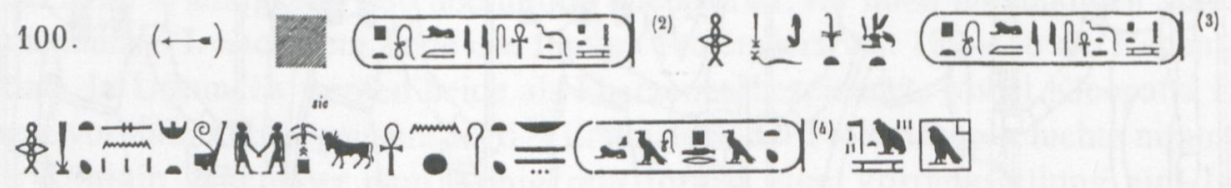

[Der König von Ober- und Unterägypten,] Ptolemaios, er lebe ewiglich, geliebt von Ptah (= Ptolemaios VI.), und sein Bruder, der König von Ober- und Unterägypten, Ptolemaios, er lebe ewiglich, geliebt von Ptah (= Ptolemaios VIII.), und ihre Schwester, die Ehefrau des Zwillingsbruders des lebenden Apis (= Ptolemaios VI.), Herrscherin, Herrin der beiden Länder, Kleopatra, die mutterliebenden Götter, <geliebt von> Hathor.

Als Ptolemaios VI. 145 starb, übernahm Ptolemaios VIII. die Herrschaft und heiratete nun seinerseits seine Schwester Kleopatra II. Sie ist in gewohnter Art vielfach hinter ihm in Ritualszenen dargestellt.

Der als siebter König der Dynastie gezählte Ptolemaios Neos Philopator wurde in der Forschung bisher als Mitregent des sechsten Ptolemäers und als dessen Nachfolger betrachtet. 145 soll er von seinem Onkel Ptolemaios VIII. während der Thronstreitigkeiten umgebracht worden sein. Dieser Sohn Ptolemaios' VI. hat in jüngster Zeit etliche Diskussionen ausgelöst: Nach M. Chauveau gibt es weder Beweise für eine Mitregentschaft noch für eine selbständige Herrschaft von Ptolemaios VII. Neos Philopator. Zudem habe Ptolemaios VI. im Jahr 145 überhaupt keinen Sohn hinterlassen. ${ }^{44}$ Letzteres wurde von $\mathrm{H}$. Heinen bestritten, der zeigen

${ }^{40}$ E. Lanciers, Die Alleinherrschaft des Ptolemaios VIII. im Jahr 164/63 v.Chr. und der Name Euergetes, in: Proceedings of the XVIII Int. Congress of Papyrology, Athens 25-31 May 1986 (ed. B.G. Mandilaras), Athens 1988, Bd. II, 405-433.

${ }^{41} \mathrm{HuB}$, Ägypten in hellenistischer Zeit, $545 \mathrm{f}$.

$42 \mathrm{PM} \mathrm{II}^{2} 403$ (15). Du Bourguet, Le temple de Deir al-Médîneh, 97, Nr. 103.

${ }^{43}$ Du Bourguet, Le temple de Deir al-Médîneh, 91, Nr. 100.

${ }^{44}$ Chauveau, BIFAO 90, 1990, 135-168. Id., BIFAO 91, 1991, 129-134. Lanciers, Die Alleinherrschaft des Ptolemaios VIII. (Anm. 40), hatte bereits darauf hingewiesen, daß Ptolemaios VII. nicht nach dem Tode des Philometor regiert haben kann. Chauveau, dessen Aufsätze von Lanciers, Some Observations on the Events in Egypt in 145 B.C., in: Simblos 1. Scritti di Storia Antica, Bologna 1995, 33-39, ergänzt wurden, warnt davor, die Numerierung der Ptolemäer zu revidieren. W. Huß, Der makedonische König und die ägyptischen Priester. Studien zur Geschichte des ptolemaiischen Ägypten, Historia Einzelschriften 85, 1994, 10, schlug vor, Ptolemaios VIII. Euergetes II. nun als Ptolemaios VII. zu zählen, Ptolemaios IX. Soter II. als Ptolemaios VIII. usw. Heinen, Der Sohn des 6. Ptolemäers, 460, empfiehlt zu Recht, es bei der seit W. Otto weithin üblichen 
konnte, daß Ptolemaios VI. sehr wohl einen Sohn hinterlassen hat, doch ob Neos Philopator mit diesem identisch war oder ob man in ihm eher Memphites, den Sohn Ptolemaios' VIII. und Kleopatras II., zu sehen hat, ist noch nicht geklärt. ${ }^{45}$ Ptolemaios Neos Philopator erscheint 145 weder im Titel des Alexander-Priesters, noch wurde er durch einen eigenen Priester in Ptolemais verehrt. Erst im Jahr 118 wurde er beim Friedensschluß des achten Ptolemäers mit seiner Schwestergemahlin Kleopatra II. rehabilitiert und in den dynastischen Königskult aufgenommen, so daß er seitdem im Titel des Alexander-Priesters zwischen dem Theos Philometor und den regierenden Theoi Euergetai steht. ${ }^{46}$

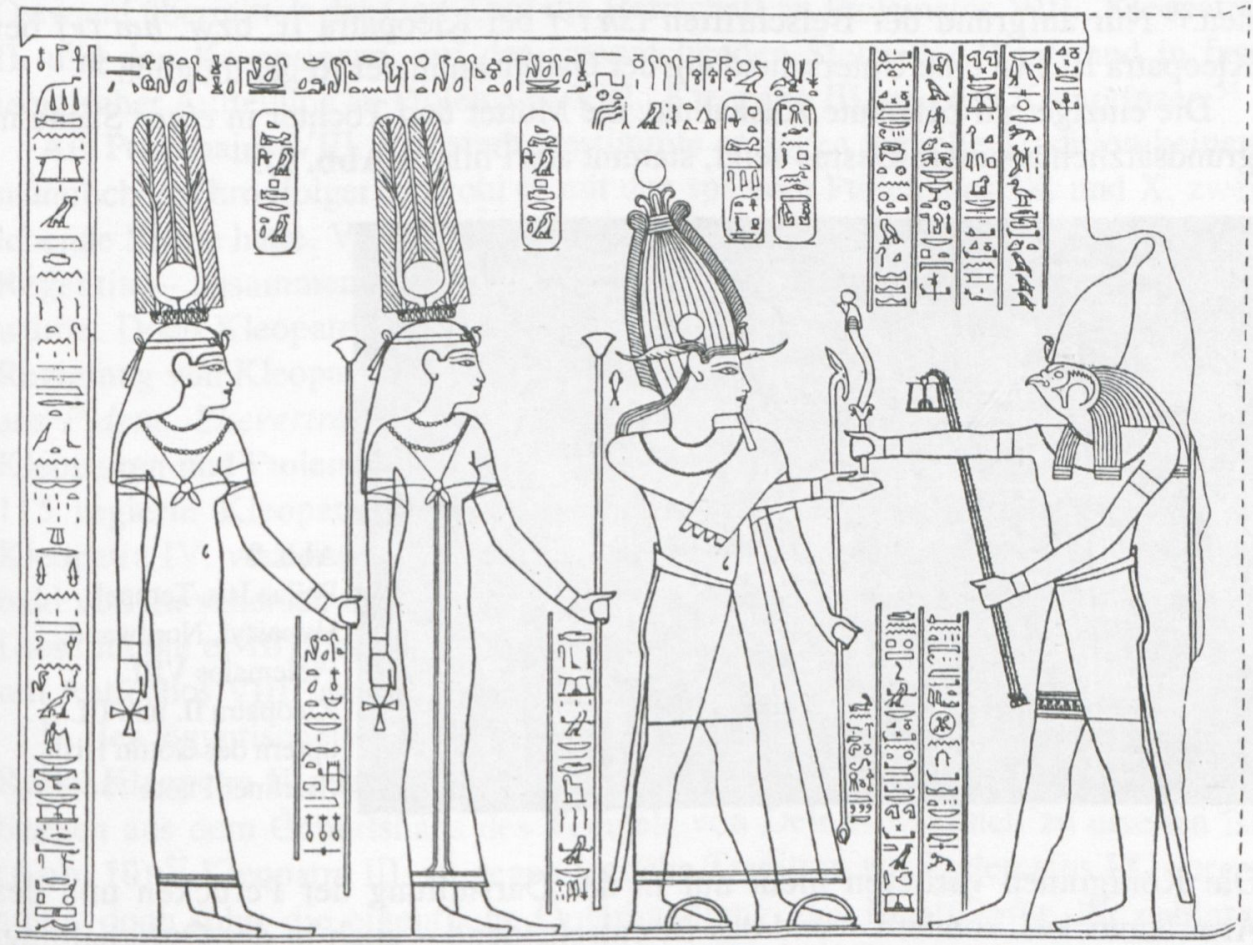

Abb. 8 Kom Ombo, Tempel des Sobek und des Haroeris, inneres Hypostyl: Ptolemaios VIII., Kleopatra II. und III. vor Haroeris (aus: De Morgan, Kom Ombo I, Nr. 462).

Die dynastischen Verhältnisse wurden zunehmend komplexer, als Ptolemaios VIII. im Jahr 142 auch noch seine Nichte Kleopatra III., die Tochter seiner Geschwister Ptolemaios VI. und Kleopatra II., heiratete. ${ }^{47}$ Durch diese EheschlieBung war eine für die gesamte Ptolemäerzeit einmalige Situation eingetreten,

Zählung zu belassen, ganz unabhängig davon, wie man die Frage der Existenz und Identität des Ptolemaios VII. Neos Philopator entscheiden mag.

45 Heinen, Der Sohn des 6. Ptolemäers, 450-456. Hölbl, Geschichte, 181, möchte in Neos Philopator Ptolemaios Memphites sehen.

46 Pestman, Chronologie, pp. 54, 146. Minas, Hieroglyphische Ahnenreihen, $153 \mathrm{f}$.

47 Zum umstrittenen Datum der Eheschließung: Minas, Hieroglyphische Ahnenreihen, 145-147. 
nämlich daß der regierende König gleichzeitig mit zwei Frauen verheiratet war, die auch noch Mutter und Tochter waren. Darstellungen der Dreierherrschaft von Ptolemaios VIII. und seinen beiden Frauen sind vielfach überliefert. Abb. 8 zeigt eine weitere Szene aus dem Tempel von Kom Ombo:48 Ptolemaios VIII., Kleopatra II. und Kleopatra III. stehen vor Haroeris. Die Mutter Kleopatra II. ist in allen Ritualszenen, die beide Königinnen zusammen zeigen, stets vor ihrer Tochter Kleopatra III. dargestellt. Ikonographisch sind beide - wie die ptolemäischen Königinnen generell - in der Regel nicht voneinander zu unterscheiden, wenngleich ihre Gewänder und ihr Schmuck im Detail leicht abweichen können. ${ }^{49}$ Nur aufgrund der Beischriften (śn.t" $f$ bei Kleopatra II. bzw. hm.t " $f$ bei Kleopatra III.) ist eine Unterscheidung der Gattinnen in der Regel möglich. ${ }^{50}$

Die einzige mir bekannte Ausnahme, die Mutter und Tochter in einer Szene in grundsätzlich anderem Gestus zeigt, stammt aus Philae (Abb. 9). ${ }^{51}$

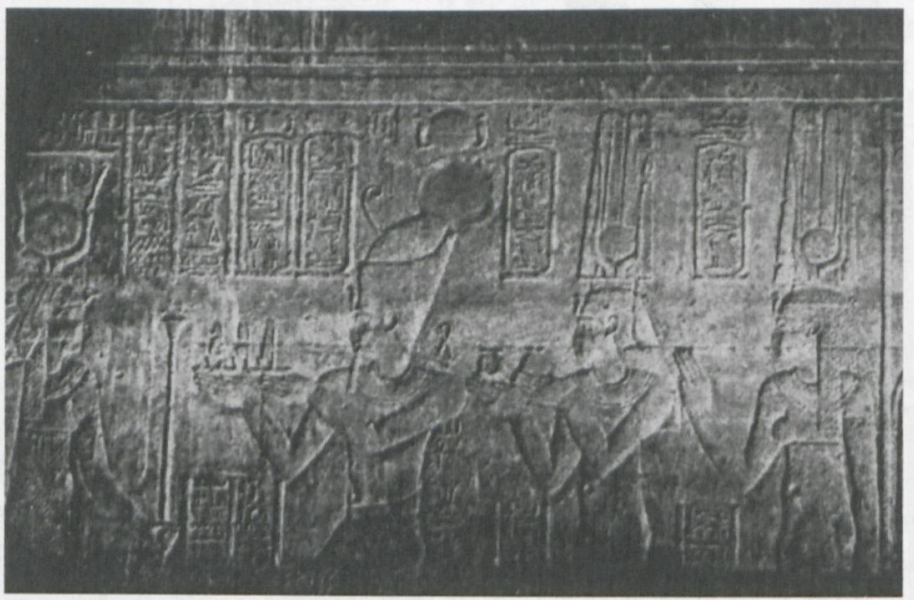

Abb. 9

Philae Isis-Tempel, Hypostyl, Nordwand: Ptolemaios VIII., Kleopatra II. und III. opfern der Göttin Isis (Berliner Photo 1341).

Die Königinnen variieren nicht nur in der Darstellung der Perücken und des Armschmuckes, sondern - und das ist entscheidend - auch in der Opferhaltung:

48 PM VI 189 (74). De Morgan, Kom Ombo I, Nr. 462.

49 So z.B. bei der Szene in Kom Ombo im inneren Hypostyl [PM VI 189 (174)], hier Abb. 8: Ptolemaios VIII. steht mit Kleopatra II. und III. vor Haroeris, wobei die Gewänder der beiden Gattinnen leicht unterschiedlich gestaltet sind; s. dazu Albersmeier, Untersuchungen zu den Frauenstatuen, 98 (mit Anm. 565), 228 (mit Anm. 340).

${ }^{50}$ Zur Unterscheidung von Kleopatra II. und III. anhand der Titel śn.t "f und hm.t " $f \mathrm{~s}$. Minas, Dekorationstätigkeit, Teil 1, 57f.; Teil 2, 89f.

${ }^{51}$ Isis-Tempel, Hypostyl, Nordwand, rechte Seite, unteres Register: Berliner Photo 1341. PM VI 234 (283). Ich danke Erich Winter für die freundliche Erlaubnis, das Berliner Photo hier zu publizieren. G. Hölbl, Altägypten im Römischen Reich II. Die Tempel des römischen Nubien, Zaberns Bildbände zur Archäologie, Mainz 2004, 14, Abb. 14. (Die Szene ist nicht, wie angegeben, links des Durchganges in den ersten Raum des Naos angebracht, sondern rechts.) 
Kleopatra II. bringt ein spezifisches Weinopfer dar, Kleopatra III. hat dagegen passiv die rechte Hand in Anbetung erhoben, die linke hängt herab. ${ }^{52}$

Mit Kleopatra II. bringt erstmalig auch eine ptolemäische Königin eine konkrete Gabe den Göttern dar, nicht nur der König. Die zweite Kleopatra ist aufgrund der spezifischen Opfergabe somit rein ikonographisch gegenüber ihrer Tochter hervorgehoben und erhält dadurch eine gewisse Vorrangstellung.

Falls beide Frauen aus Platzgründen nicht in einer Szene abgebildet werden konnten, so wurden sie in spiegelbildlich entsprechenden Szenen angebracht, wie an der westlichen und östlichen Außenwand des Naos von Edfu: ${ }^{53}$ Auf der Ostwand übermittelt der Gott Thot die Herrschaft an Ptolemaios VIII., Kleopatra II. und den Kronprinzen, auf der entsprechenden Stelle der Westwand in fast identischer Aufteilung an Ptolemaios VIII., Kleopatra III. und den Kronprinzen. ${ }^{54}$

Als Ptolemaios VIII. 116 starb, bestimmte er gegen jegliche Tradition keinen männlichen Thronfolger, obwohl er mit den späteren Ptolemaios IX. und X. zwei lebende Söhne hatte. Vielmehr bestimmte er seine jüngere Frau Kleopatra III. als Regentin - zusammen mit demjenigen der beiden Söhne, den sie auswählen würde. Doch Kleopatra II. ließ sich nicht abdrängen und wurde anfangs in die Regierung von Kleopatra III. und Ptolemaios IX. Soter II. miteinbezogen, wie wir aus P.dem. Eheverträge 39 vom 29. Oktober 116 wissen, der nach beiden Kleopatren und Ptolemaios IX. datiert ist. ${ }^{55}$ Nach dem Tode ihrer Mutter im Jahr 115 regierte Kleopatra III. nun mit Ptolemaios IX., der anfangs noch mit Kleopatra IV. verheiratet war. Wohl auf Drängen von Kleopatra III. ließ er sich bald von ihr scheiden und heiratete seine jüngere Schwester Kleopatra V. Selene. Diese mußte er 107 bei seiner Flucht aus Alexandria zurücklassen, woraufhin sie mit Antiochos VIII. von Syrien verheiratet wurde. ${ }^{56}$

In den ägyptischen Tempelreliefs spielen Kleopatra IV. und V. kaum eine Rolle, Kleopatra III. dafür eine um so größere, wie am Beispiel einer der beiden Szenen aus dem Geburtshaus des Tempels von Deir el-Medineh zu ersehen ist (Abb. 10): ${ }^{57}$ Kleopatra III. ist gegen jegliche Tradition vor Ptolemaios IX. dargestellt, doch führt die eigentliche Opferhandlung, das Maat-Opfer, ihr dahinter stehender Sohn aus. ${ }^{58}$

52 Aufgrund der Abarbeitungen der Reliefs von Oberschenkelhöhe abwärts ist nicht mehr zu erkennen, ob sie in der linken Hand ein Objekt gehalten hat. Denkbar wäre ein Anchzeichen wie in Abb. 8, 15-18.

53 Edfou X, Pl. 93, XIII, Pl. 446 (Ost-Wand); Edfou X, Pl. 87, XIII, Pl. 439 (West-Wand).

${ }^{54}$ Es ist unklar, um welchen Knaben es sich bei dem Kronprinzen handelt, s. Minas, Dekorationstätigkeit, Teil 2, $93 \mathrm{f}$.

55 S. auch Pestman, Chronologie, 64-66.

56 Hölbl, Geschichte, 185 und 189.

$57 \mathrm{PM} \mathrm{II}^{2} 407$ (34). Du Bourguet, Le temple de Deir al-Médîneh, Nr. 183. In der zweiten Szene (Nr. 182) ist der König ohne Kleopatra III. dargestellt.

58 S. Cauville \& D. Devauchelle, Le temple d'Edfou: Étapes de la construction - Nouvelles données historiques, $R d E$ 35, 1984, 47-50, sehen nicht in Kleopatra III., sondern in Kleopatra II. die Mutter des neunten Ptolemäers, womit sie sich von der communis opinio abheben. 


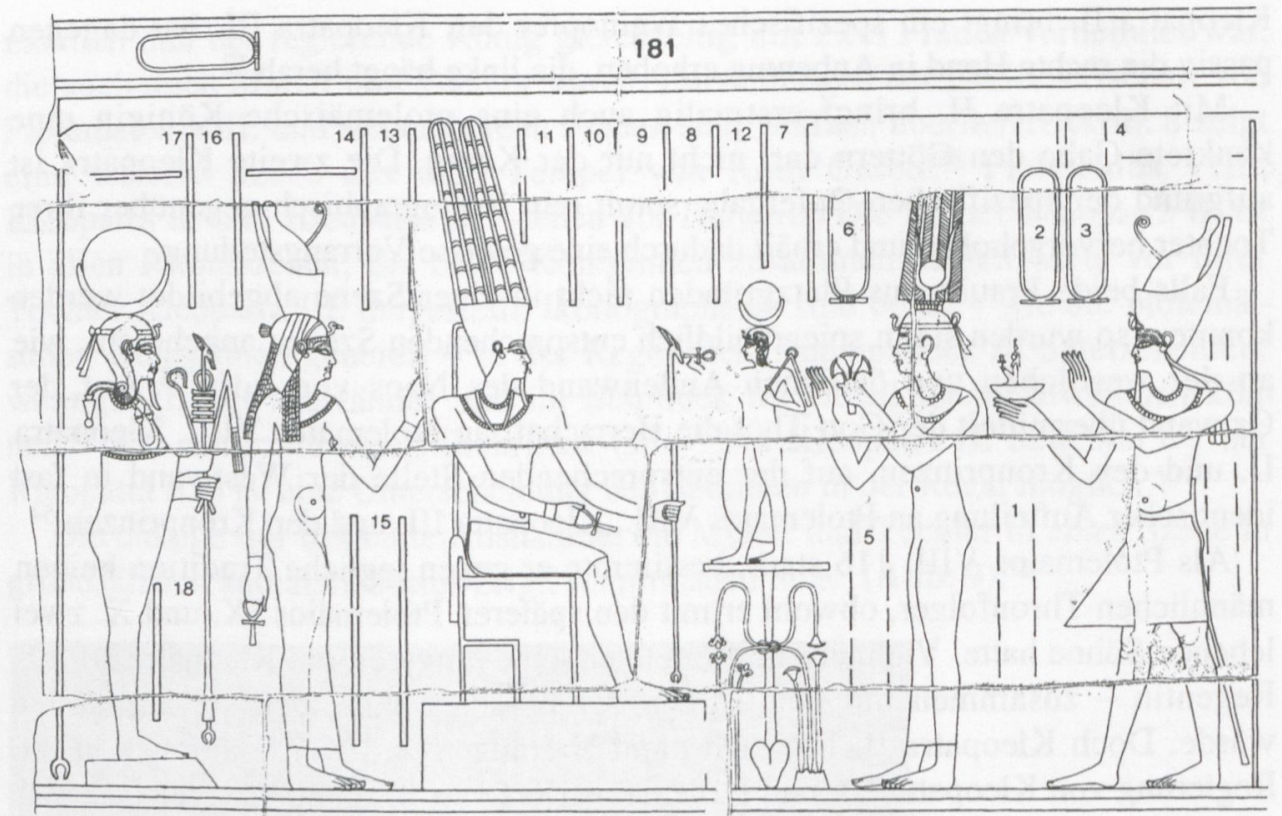

Abb. 10 Deir el-Medineh, Tempel der Hathor, Mammisi: Kleopatra III. und Ptolemaios IX. Soter II. zusammen mit Semataui vor der thebanischen Triade, Amun-Re, Mut und Chons (aus: Du Bourguet, Le temple de Deir al-Médîneh, 171, Nr. 183).

Auch in der darüberliegenden Friesinschrift wird Kleopatra III. vor der fünfteiligen, historisch so aussagekräftigen Königstitulatur ihres Sohnes genannt. ${ }^{59}$ Sie wird als weiblicher Horus charakterisiert und trägt damit einen Titel, der seit Berenike II. die ptolemäischen Königinnen als Mitregentinnen auszeichnet:

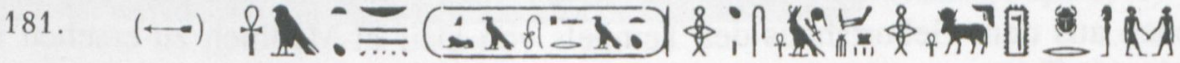

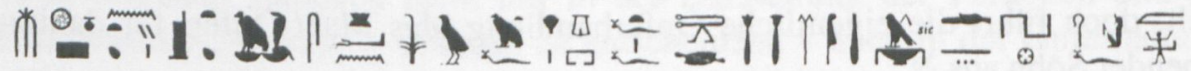

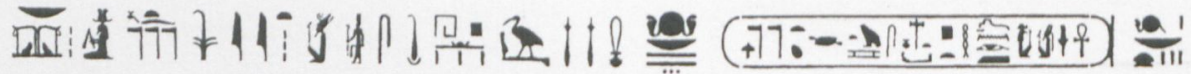

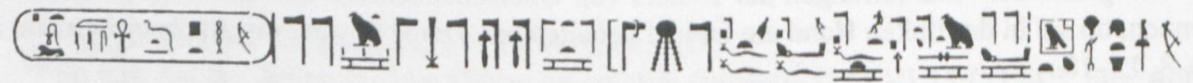

(Es lebe) der weibliche Horus, Herrin der beiden Länder, Kleopatra, zusammen mit ihrem Sohn, (es lebe) der Horus, heilig an Geburt zusammen mit dem lebenden Apis, göttlich an Gestalt, Zwilling der Geburtsstätte des Sohnes der Isis; die beiden Herrinnen, den seine Mutter auf dem Thron seines Vaters eingesetzt hat, der das Erbe der beiden Länder in Triumph erobert hat, Gold(horus), Herr Ägyptens, der in Jubel herrscht, Herr der Sedfeste (wie) Tatenen (und) die früheren Könige, Vater der Götter, Fürst, der die Ge-

${ }^{59}$ Du Bourguet, Le temple de Deir al-Médîneh, 168, Nr. 181. 
setze festsetzt wie der zweimal große Thot, König von Ober- und Unterägypten, Herr der beiden Länder, Erbe des wohltätigen Gottes (= Ptolemaios VIII.) und der Göttin, die ihre Mutter liebt, Retterin (= Kleopatra III.), erwählt von Ptah, der die Maat des Re verwirklicht, lebendes Abbild des Amun, Sohn des Re, Herr der Kronen, Ptolemaios, geliebt von Ptah, die beiden mutterliebenden Götter, geliebt von den beiden Geschwistergöttern, den beiden wohltätigen Göttern, den beiden vaterliebenden Göttern, den beiden erscheinenden Göttern, dem Gott, der seinen Vater ehrt, dem Gott, der seine Mutter liebt, dem jugendlichen Gott, der (seinen) Vater liebt, dem wohltätigen Gott, der Göttin, die ihre Mutter liebt, den beiden Göttern, die (ihre) Mutter lieben, und Hathor, Oberste von Waset, Herrin des Westens. ${ }^{60}$

Weitere Beispiele aus einer Vielzahl von Darstellungen Kleopatras III. im indigenen Tempelmilieu sollen die Umsetzung der Machtposition Kleopatras' III. in ägyptischen Tempelreliefs erläutern. Das erste stammt aus dem Tempel der Nechbet in El-Kab: Kleopatra III. ist auf der Fassade des Sanktuars an beiden Seiten der Eingangstür allein opfernd mit zwei Sistren in den Händen dargestellt, also ohne spezifische Opfergabe. ${ }^{61}$ Abb. 11 zeigt die westliche der beiden Szenen. ${ }^{62}$

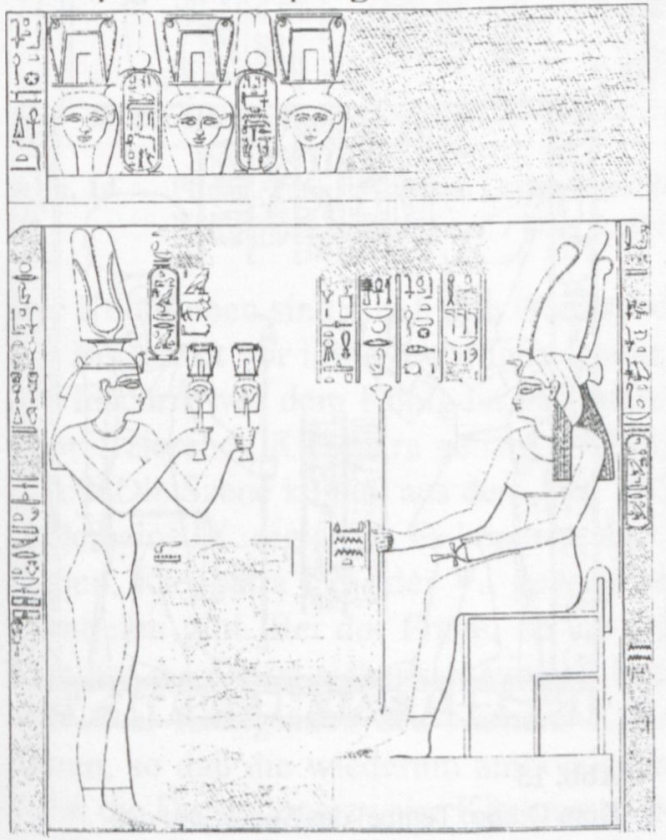
Abb. 11
El-Kab, Tempel der Nechbet, Fassade des Sanktuars: Kleopatra III. vor Nechbet (aus: R. Lepsius, Denkmaeler aus Aegypten und Aethiopien VI, Berlin 1849-1858, Pl. 40b).

Kleopatra III. trägt einen maskulinen Horusnamen ("starker Stier") und wird als weiblicher Horus bezeichnet. Beides unterstreicht ihre Stellung als Königin, die jedoch nicht allein und ganz eigenständig regieren konnte. Im Fries über ihrer Darstellung ist nämlich der Thron- und Eigenname Ptolemaios' IX. eingemeißelt, womit der Bezug zum Pharao offensichtlich ist. Der König selbst ist auf dem Ein29-31

${ }^{60}$ Zur Diskussion der Ahnenreihe s. Minas, Hieroglyphische Ahnenreihen, Dok. 57, bes.

${ }^{61}$ Derchain, El Kab I, S. 6*-7*, Pl. 14; s. auch Hölbl, Weiblicher Pharao, 93.

${ }^{62}$ LD IV $40 \mathrm{~b}=$ Derchain, El Kab I, S. 7*. 
gangstor des Tempels allein opfernd abgebildet, ${ }^{63}$ jedoch sind die Kartuschen leer geblieben; vielleicht waren sie ursprünglich in Farbe aufgetragen. Der Pharao ist somit für Tempelbesucher zuerst zu sehen, doch ist die Königin an der Sanktuarfassade, also im näheren Umkreis der Gottheit, angebracht.

Die Königin ist neben Urkunden auch in Tempelreliefs an die erste Stelle getreten, wie das Zeugnis aus Deir el-Medineh zeigt. In El-Kab war sie zusätzlich an exponierter Stelle dargestellt, näher bei den Göttern als der König selbst.

Ein zweites Beispiel bezeugt, daß sich Kleopatra III. sogar soweit emanzipieren konnte, daß sie die eigentliche Opfergabe präsentiert: In einer der beiden Szenen einer Säule aus dem Tempel von Kom Ombo ${ }^{64}$ ist Kleopatra III. nicht nur allein opfernd, sondern auch mit spezifischer Opfergabe dargestellt (Abb. 12). In der entsprechenden zweiten Szene ist Ptolemaios IX. zu sehen (Abb. 13). Beide Herrscher sind räumlich voneinander getrennt, was Kleopatra III. zu einer eigenständigeren Rolle verhilft und ihre Macht demonstriert. ${ }^{65}$ Letztendlich ist sie aber nur Mitregentin, kein eigenständig regierender Pharao, was alle angeführten Beispiele belegen.

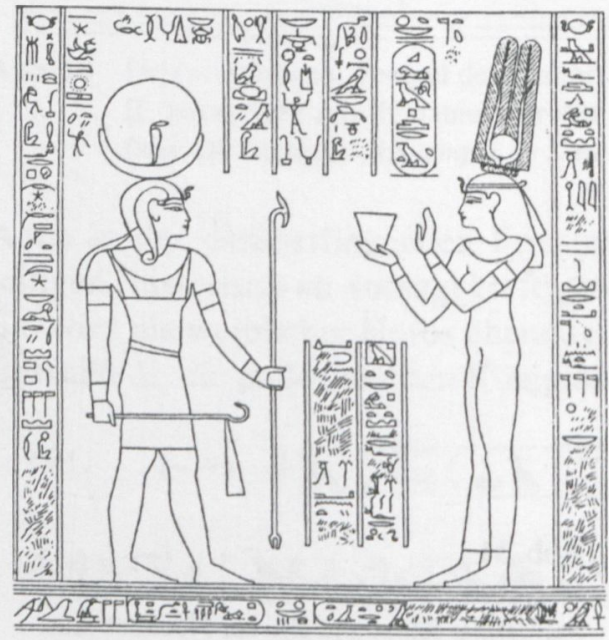

Abb. 12

Kom Ombo, Tempel des Sobek und des Haroeris: Kleopatra III. vor Chons (aus: De Morgan, Kom Ombo II, Nr. 1063).

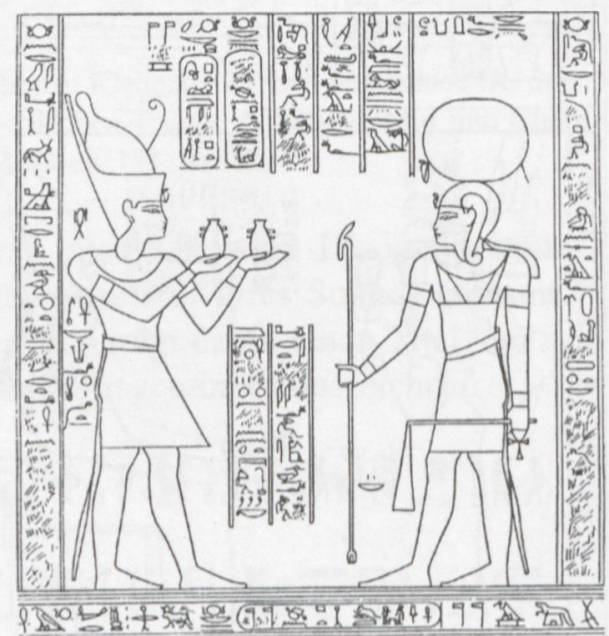

Abb. 13

Kom Ombo, Tempel des Sobek und des Haroeris: Ptolemaios IX. (aus: De Morgan, Kom Ombo II, Nr. 1064).

${ }^{63}$ LD IV 68 = Derchain, El Kab I, S. 1*-5*, PI. 11.

64 PM VI 201, Miscellaneous, blocks, etc.: "Red sandstone columns, Ptolemy VI Philometor, found in sebakh". De Morgan, Kom Ombo II, Nr. 1063-1064 auf p. 341 und Taf. auf p. 345.

65 Als ein weiteres Beispiel dieser Machtdemonstration kann Edfu dienen: Kleopatra III. ist allein im unteren Register der östlichen Außenwand des Pronaos mit Sistrum und Menit vor Hathor dargestellt, in den sonstigen Reliefszenen dieser Wand Ptolemaios IX. (Edfou X, Pl. 107). 
Im Ostturm des Ersten Pylons von Philae ist Ptolemaios IX. auf der Ostwand in der unteren von zwei Szenen vor zwei Königinnen dargestellt, die mit Wein und Weihrauch unterschiedliche spezifische Opfergaben überreichen (Abb. 14).

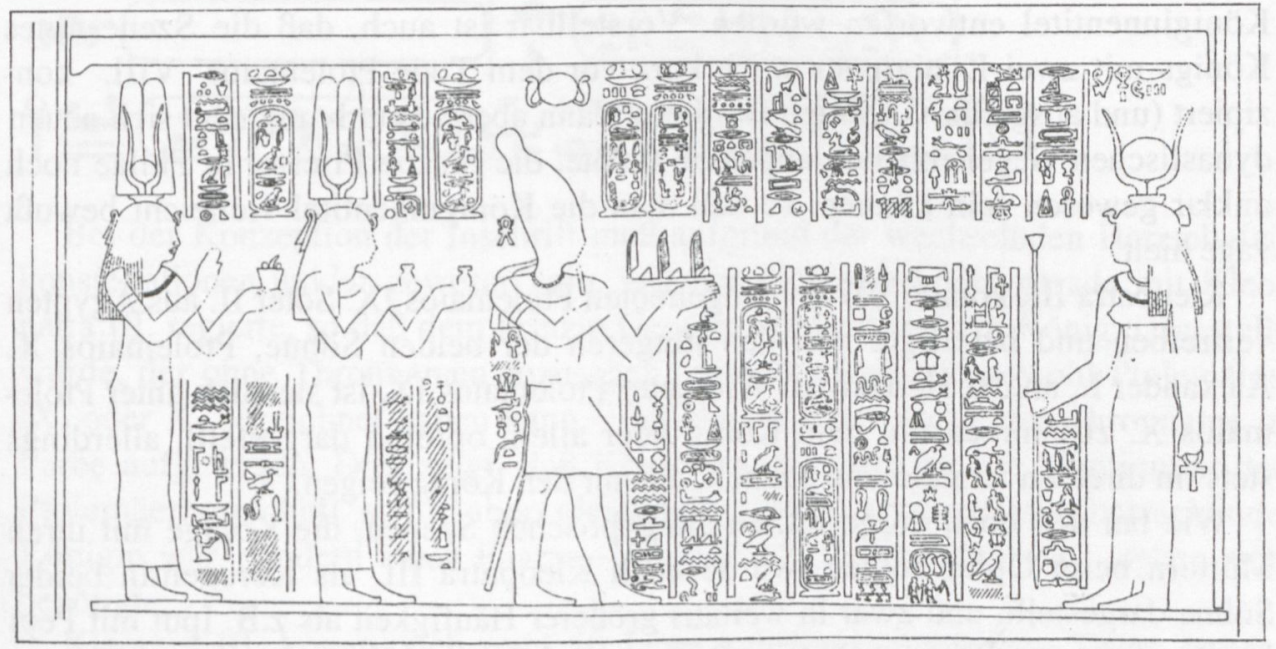

Abb. 14 Philae, Tempel der Isis, Ostturm des Ersten Pylons: Ptolemaios IX. Soter II. mit zwei Königinnen vor Isis (aus: Philae I, Abb. 100).

Die Königinnen sind durch ihre identischen Titel (s $3 . t-R^{c}$ bzw. $\left.R^{c} j . t^{66} n b . t-t 3 . w j\right)$ in der Beischrift vor ihren jeweiligen Darstellungen nicht näher zu bestimmen. ${ }^{67}$ In der Inschrift vor dem König ist nach dem Königsnamen nur eine, nicht näher zu identifizierende Kleopatra genannt. ${ }^{68}$ Folgende Interpretationsansätze sind möglich:69 Die Szene könnte aus dem Jahr 116 stammen, als Kleopatra II. und III. mit Ptolemaios IX. regierten. Es könnten aber auch Kleopatra III. und eine seiner Ehefrauen, Kleopatra IV. oder V., gezeigt sein, wofür es allerdings keine weiteren Parallelen gibt. Bei der Frage, ob ein oder zwei Königinnen an der Regierung beteiligt waren, ist sicherlich auch zu bedenken, daß man seit 142 gewohnt war, $\mathrm{da}$ zwei Königinnen des Namens Kleopatra mit Ptolemaios VIII. geherrscht hatten, so daß die wiederum ambivalenten Herrschaftsverhältnisse unter seinem Sohn die Darstellung zweier Königinnen bedingt haben könnten.

Die weiteren Inschriften und Szenen des Ostturms geben wenig Aufschluß über die beiden Königinnen. Die beiden Pfostentexte des Eingangs zum Ostturm (Philae I, Abb. 98a-b) stammen bereits aus der Zeit des sechsten Ptolemäers. Auf der zweiten Szene der Ostwand (Philae I, Abb. 99) ist Ptolemaios IX. allein

\footnotetext{
66 So Devauchelle, RdE 40, 1989, 190. Hölbl, Weiblicher Pharao, 88 (Anm. 2), 92 (Anm. 42).

67 Philae I 173,16 und 174, 1.

68 Philae I 173, 11.

69 Nach Gauthier, LdR IV, 333 (LXXXIII C), 364 (LXII), sind Kleopatra III. und IV. dargestellt, nach Hölbl, Weiblicher Pharao, 92, und Devauchelle, RdE 40, 1989, 190, Kleopatra II. und III., nach Murnane, Ancient Egyptian Coregencies, 100f., Kleopata III., IV. oder V. Quaegebeur, Reines ptolémaïques, 255f. (mit Anm. 66), ill. L, enthält sich einer Zuweisung.
} 
opfernd zu sehen, auf der einzigen Szene der Südwand (Philae I, Abb. 101) mit nur einer Kleopatra, die wieder nicht eindeutig durch ihre Titel identifizierbar ist. ${ }^{70}$ Man kann vermuten, daß unter den Priestern von Philae Verwirrung über die Identität der Königinnen geherrscht haben könnte, als die Inschriften und Königinnentitel entworfen wurden. Vorstellbar ist auch, daß die Szene eines Königs mit zwei Königinnen noch kurz vor dem Tode Ptolemaios' VIII. konzipiert (und ausgeführt) worden ist, dieser dann aber verstarb und man sich neuen dynastischen Gegebenheiten anpassen mußte, die für die Priester in Philae noch unklar gewesen sein können, so daß man die Königinnentitel vielleicht bewußt vage hielt.

Kleopatra III. konnte 107 den ungeliebten Ptolemaios IX. Soter II. aus Ägypten vertreiben und beteiligte nun den jüngeren der beiden Söhne, Ptolemaios X. Alexander I., an der Herrschaft. Wie unter Ptolemaios IX. ist sie auch unter Ptolemaios X. zusammen mit dem König oder allein opfernd dargestellt, allerdings stets im direkten Umfeld von Szenen, die nur den König zeigen.

Wie bei den oben vorgestellten altägyptischen Szenen, die Könige mit ihren Müttern beim Opfer zeigen, wurde auch Kleopatra III. als Koregentin beider Söhne dargestellt, und zwar in weitaus größerer Häufigkeit als z.B. Iput mit Pepi I. oder Tuja mit Ramses II. Wie Radwan für Ramses II. feststellte (s.o. Anm. 15-16), soll die Darstellung der Mutter hinter dem regierenden König nicht heißen, daß der König unverheiratet war, sondern vielmehr die Stellung der Mutter hervorheben. Dies trifft auch auf Ptolemaios IX. und X. zu. Im Unterschied zu Ramses II. waren sie gegenüber der Mutter in ihrer Machtposition wesentlich mehr eingeschränkt, d.h. Kleopatra III. wesentlich mächtiger als Tuja.

Die Thronwirren des ausgehenden 2. Jhs. und des beginnenden 1. Jhs. unter Ptolemaios IX. und X. spiegeln sich in einigen Szenen wider, die Kleopatra III. mit unbenanntem Ptolemäer (IX. oder X.) zeigen, so z.B. in Edfu im unteren Register der Innenseite der Umfassungsmauer (Abb. 15): ${ }^{71}$

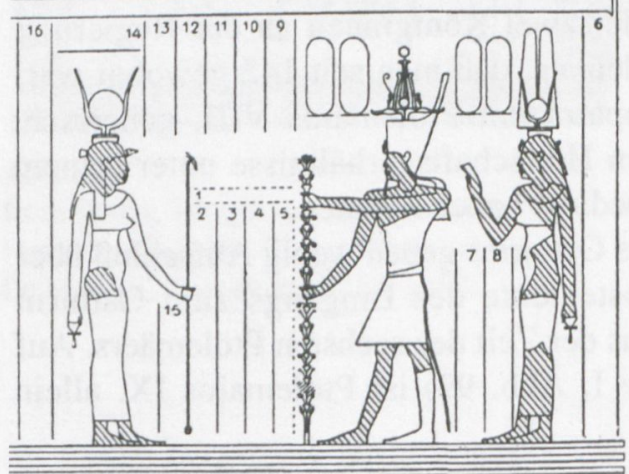

Abb. 15

Edfu, Horus-Tempel, Umfassungsmauer: Ptolemaios IX. oder X. mit Kleopatra III. vor Hathor (aus: Edfou X, Pl. 152).

${ }^{70}$ In Philae I 171, 173f. (ad Abb. 99-101), wird der König als Ptolemaios X. bezeichnet, doch sind die Kartuschen Ptolemaios IX. Soter II. zuzuweisen.

${ }^{71}$ Edfou VI 246f.; X, Pl. 152, XIV; PI. 587; [PM VI 164 (316)-(323)]. 
Bei dem vor Kleopatra III. stehenden König ist nur der Eigenname 'Ptolemaios' in die Kartusche geschrieben worden, der spezifizierende Thronname fehlt, wohingegen die Königin eindeutig als Kleopatra III. definiert ist:

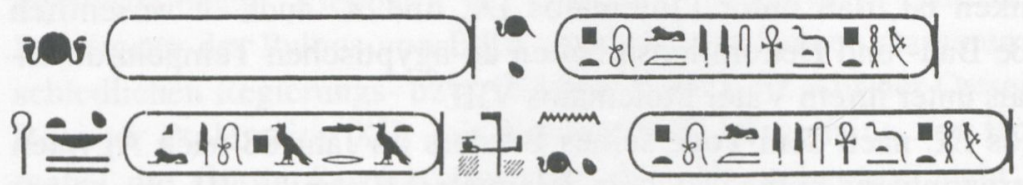

Bei der Konzeption der Inschrift muß aufgrund der wechselnden Herrschaftskonstellationen unklar gewesen sein, welcher Ptolemäerkönig gerade mit Kleopatra III. regierte, so daß dem Prinzip Genüge geleistet und ein König dargestellt wurde, der ohne Thronnamen sozusagen 'neutral' blieb und sowohl Ptolemaios IX. oder X. bezeichnet haben kann. ${ }^{72}$ Möglicherweise wurde der Thronname in Farbe aufgetragen. Dies zeigt, daß Kleopatra III. zwar für die Kontinuität der Ptolemäerherrschaft steht, aber gleichzeitig keine eigenständig herrschende Königin war, sondern einen Pharao - wenngleich marionettenhaft - neben sich benötigte.

Kleoptra III. konnte sich rund 40 Jahre auf dem ägyptischen Thron halten. Parallel zu den ägyptischen Tempelreliefs wird ihre Machtposition auch im Dynastiekult deutlich, und zwar durch die Schaffung zusätzlicher Priesterämter. Sie beeinflußte den eponymen Kult mehr als jede andere Ptolemäerkönigin, letztlich soweit, daß er seine Bestimmung, die Bedeutung und Legitimität der Dynastie zu erhöhen, verlor und in der zweiten Regierungsperiode Ptolemaios' IX. Soter II. (88-80) völlig in summarischen Kurzformeln unterging. ${ }^{73}$ Erst die Ermordung Kleopatras III. im Jahr 101 durch ihren Sohn Ptolemaios X. setzte ihrer Politik ein Ende. Die Königin hatte sich so in ihrem Machtstreben durchgesetzt, daß sie allein opfernd dargestellt werden konnte. Damit wird ihre dynastische Machtposition auch in den ägyptischen Tempeln offensichtlich. Wie erstmals ihre Mutter Kleopatatra II. setzte sich auch Kleopatra III. über das männliche Vorrecht hinweg, ein spezifisches Opfer auszuführen.

\section{Kleopatra Berenike III.}

Nach dem Tode Kleopatras III. heiratete Ptolemaios X. seine Nichte Kleopatra Berenike III., die Tochter Ptolemaics' IX. und Kleopatras IV. Auch sie wurde allein und mit spezifischer Opfergabe dargestellt, so z.B. auf der Außenseite der Umfassungsmauer in Edfu, wo sie beim Wein- und Milch-Opfer vor Hathor und Harsomtus zu sehen ist. ${ }^{74}$ In den fortlaufenden Szenen ist wieder Ptolemaios X. dargestellt, doch konnte, nach dem Edfu-Relief zu urteilen, Kleopatra Berenike III. offensichtlich eine ähnliche Machtposition behaupten wie Kleopatra III., war

72 Zu dieser Problematik s. A. Egberts, A Note on the Building History of the Temple of Edfu, RdE 38, 1987, 59f., der letztendlich Ptolemaios IX. in dem König sehen möchte.

${ }^{73}$ Minas, Hieroglyphische Ahnenreihen, 155-161, $191 \mathrm{f}$.

${ }^{74}$ Edfou XIV, Pl. 642; VII 88-90 = PM VI 166 (334)-(335) = LdR IV 389. 
dem König also faktisch nicht mehr untergeordnet. Allerdings erlangte sie historisch nicht die Bedeutung ihrer Großmutter Kleopatra III. ${ }^{75}$ Kleopatra Berenike III. ist in Reliefs weitaus seltener dargestellt als ihre große Ahnherrin, wobei zu bedenken ist, daß unter Ptolemaios IX. und X. auch in wesentlich geringerem Maße Bau- und Dekorationsarbeiten an ägyptischen Tempeln durchgeführt wurden als unter ihrem Vater Ptolemaios VIII.

Als Ptolemaios IX. nach dem Tode seines Bruders im Jahr 88 nach Ägypten zurückkehrte, ernannte er seine Tochter Kleopatra Berenike III. zu seiner Mitregentin. ${ }^{76}$ Nach seinem Tod im Jahr 80 übernahm sie zuerst allein die Herrschaft über Ägypten, stellte also wie Kleopatra III. ein Kontinuum der ptolemäischen Herrschaft dar. Da nach ägyptischer Weltanschauung eine Königin nicht alleine regieren sollte, heiratete sie nach etwa sechs Monaten ihren Stiefsohn Ptolemaios XI. Alexander II. Dieser ließ sie nach nur wenigen Tagen umbringen, woraufhin die Alexandriner ihn ermordeten. ${ }^{77}$

\section{Kleopatra VI. Tryphaina}

Der nun folgende Ptolemaios XII. Neos Dionysos war ein Sohn des neunten Ptolemäers. Bald nach der Thronbesteigung im Jahr 80 heiratete er seine Schwester Kleopatra VI. mit dem Beinamen Tryphaina, die 'Prunkende', ${ }^{78}$ die im Jahr 69/68 in Ungnade fiel. ${ }^{79} 58$ ging Ptolemaios XII. ins Exil nach Rom, woraufhin Kleopatra VI. und die gemeinsame Tochter Berenike IV. an die Macht kamen, doch verstarb Kleopatra VI. bald darauf.

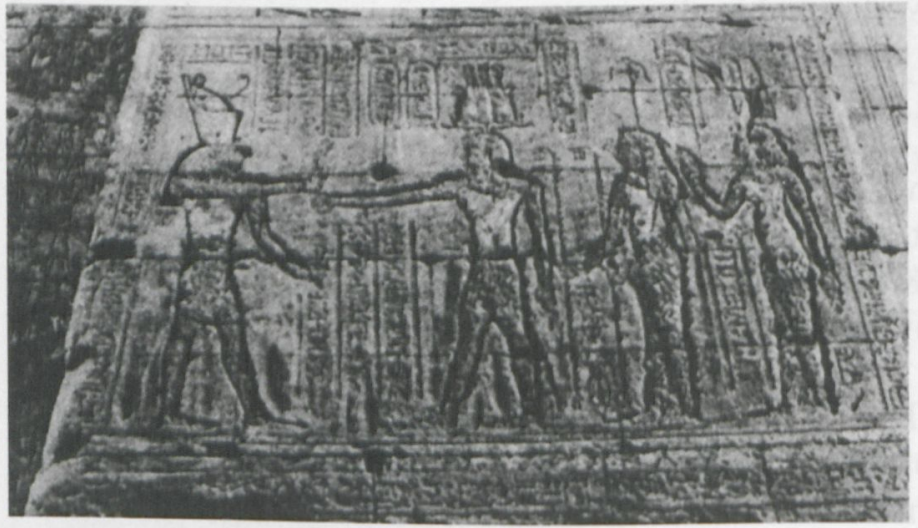

Abb. 16

Edfu, Horus-Tempel, Durchgang des Pylons, Ostwand: Ptolemaios XII., die Göttin Seschat und Kleopatra VI. Tryphaina vor Horus (aus: Quaegebeur, Une scène historique méconnue, 600 , ill. 2).

75 Angesichts ihrer Position ist es um so erstaunlicher, daß Kleoptra Berenike III. im Artikel Hölbls, Weiblicher Pharao, keine Erwähnung findet.

76 Hölbl, Geschichte, 189, 191.

77 Hölbl, Geschichte, 193f.

${ }^{78}$ Zur positiven Bedeutung von Tryphaina bzw. Tryphe s. H. Heinen, Die Tryphè des Ptolemaios VIII. Euergetes II. Beobachtungen zum ptolemäischen Herrscherideal und zu einer römischen Gesandtschaft in Ägypten (140/39 v.Chr.), in: Althistorische Studien. Hermann Bengtson zum 70. Geburtstag dargebracht von Kollegen und Schülern (ed. H. Heinen), Historia Einzelschriften 40, Wiesbaden 1983, 116-128.

${ }^{79}$ Hölbl, Geschichte, 195. 
Berenike IV. wurde nach der Rückkehr ihres Vaters hingerichtet und ist aufgrund der damnatio memoriae in keiner ägyptischen Tempelszene erhalten oder hieroglyphisch belegt. Kleopatra VI. Tryphaina jedoch ist in Edfu zu finden: Die im Durchgang des Pylons von Edfu angebrachten Szenen stammen aus zwei unterschiedlichen Regierungs- bzw. Dekorationsphasen: Auf der Ostseite ist im vierten Register Ptolemaios XII. mit Kleopatra VI. Tryphaina vor Horus dargestellt, wobei die Göttin Seschat zwischen dem Herrscherpaar steht (Abb. 16). Die Königin trägt die typische Doppelfederkrone und ist in der Kartusche mit 'Kleopatra, genannt Tryphaina' bezeichnet. Die Darstellung muß aus der Zeit vor Kleopatras Sturz im Jahr 69/68 stammen, doch ist die Königin nun wieder eindeutig passiv hinter dem König zu sehen, also mit verringerter Machtposition als Kleopatra III. und Kleopatra Berenike III. ${ }^{80}$

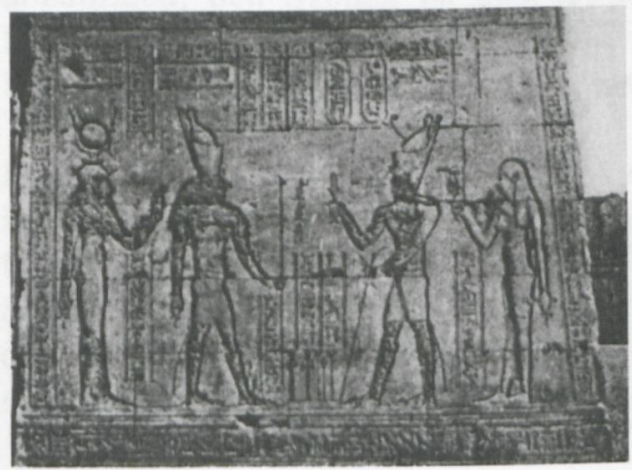

Abb. 17

Edfu, Horus-Tempel, Durchgang des Pylons, Ostwand: Ptolemaios XII. und Kleopatra VI. vor Horus und Hathor (Edfou XIV, Pl. 660).

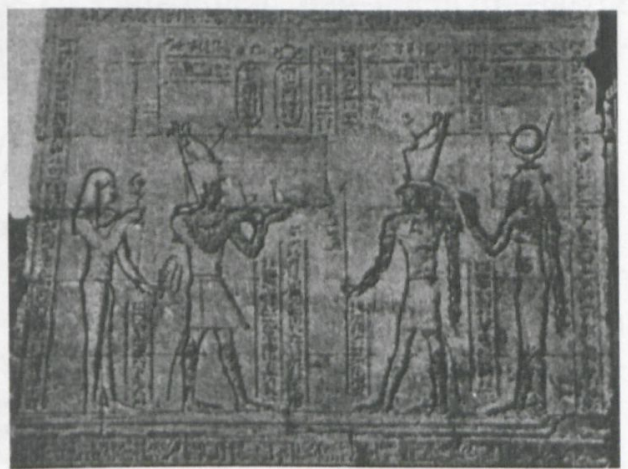

Abb. 18

Edfu, Horus-Tempel, Durchgang des Pylons, Westwand: Ptolemaios XII. und Kleopatra VI. vor Horus und Hathor (Edfou XIV, PI. 658).

Schräg unterhalb dieser Szene sind auf jeder Seite des Durchganges im untersten Register zwei ungewöhnliche Königinnen-Darstellungen zu finden (Abb. 1718). ${ }^{81}$ Die hinter Ptolemaios XII. stehende Herrscherin trägt, völlig ungewöhnlich, keine königlichen Insignien, also keine Krone und keinen Uräus; ${ }^{82}$ zudem blieb sie namenlos. Da die Dekoration des Tores vor 58, als Ptolemaios XII. nach Rom ins Exil ging, fertiggestellt war, ${ }^{83}$ wird wohl bewußt auf eine Definierung der Königin verzichtet worden sein, da Kleopatra VI. Tryphaina schon in Ungnade gefallen war. In diesen drei Szenen am Pylon von Edfu wurden Macht und Ohnmacht einer ptolemäischen Königin visuell ausgedrückt.

${ }^{80}$ PM VI 123 (16). Edfou VIII 62f. Quaegebeur, Une scène historique méconnue, 595-608.

${ }^{81}$ Westseite: PM VI $123(11)=$ Edfou VIII, 25f. = Edfou XIV, Pl. 658; Ostseite: PM VI 123 (14) = Edfou VIII, 32-34 = Edfou XIV, Pl. 660 .

82 Vgl. Abb. 3 (Stele Berlin Inv. Nr. 15699): Im Gegensatz zu Ahmes trägt Hatschepsut nur einen Kronenuntersatz, doch sind hier für das Fehlen der Krone nur Platzgründe verantwortlich.

${ }^{83}$ So schlüssig Quaegebeur, Une scène historique méconnue, 595-608. 


\section{Kleopatra VII.}

Im April 55 kam Ptolemaios XII. nach Alexandria zurück und ließ seine Tochter Berenike (Kleopatra) IV. hinrichten. Im Jahr 52/51 ernannte er seine Tochter Kleopatra VII. zu seiner Koregentin, ${ }^{84}$ wohl auch, um die dynastische Kontinuität zu sichern. So ist Kleopatra VII. in den Krypten von Dendera hinter Neos Dionysos zu sehen, was dafür spricht, daß die Krypten in der kurzen Zeit dekoriert worden sind, in der Vater und Tochter gemeinsam regiert haben. ${ }^{85}$ Insgesamt ist Kleopatra VII. in Dendera in mindestens 73 Szenen dargestellt, wobei sie neben der typischen Doppelfederkrone der Königinnen auch mehrfach eine Kompositkrone trägt, sehr ähnlich derjenigen Arsinoes II. (Abb. 19). ${ }^{86}$ Somit ist sie wie die Schwestergemahlin des zweiten Ptolemäers von den anderen Ptolemäerköniginnen schon rein ikonographisch hervorgehoben.

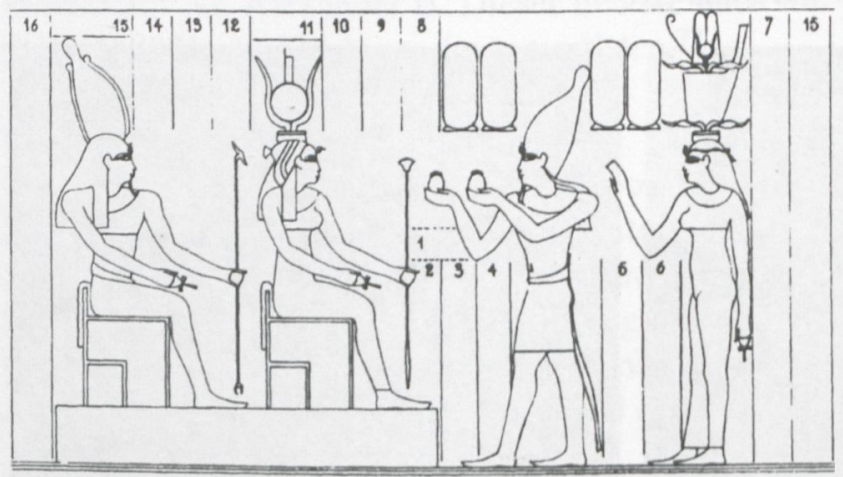

Abb. 19

Dendera, Krypten: Ptolemaios XII. und Kleopatra VII. vor Isis und Osiris (aus: É. Chassinat, Le temple de Dendara, Le Caire [IFAO] 1934, Bd. II, 40f., Pl. 98).

Kleopatra VII. regierte nach dem Tod ihres Vaters im Jahr 51 erst mit ihrem Bruder Ptolemaios XIII., dann mit Ptolemaios XIV., schließlich ab 44 mit ihrem Sohn Ptolemaios Kaisar(ion), dem 47 geborenen Sohn Caesars.

Die letzte Ptolemäerkönigin ist besonders durch die beiden überdimensional großen Darstellungen mit Kaisar(ion) auf der Tempelrückwand des HathorTempels von Dendera bekannt, ${ }^{87}$ die J. Ray folgendermaßen beschreibt: 88 "This is hardly a conventional piece of wall-filling; on the contrary, it is designed to make a strong and distinct statement. ... the contribution of Cleopatra VII to this site can never be described as a lifeless or mechanical continuation."

In Dendera steht Kleopatra VII. auf traditionelle Art hinter dem KindKoregenten und Sohn, anders als im Geburtshaus von Armant, das von 44-30

${ }^{84} \mathrm{Hölbl,} \mathrm{Geschichte,} 204$.

85 Quaegebeur, Une scène historique mécónnue, 605, n. 43. Id., Cléopâtre VII et le temple de Dendara, GM 120, 1991, 49-72. E. Winter, A Reconsideration of the Newly Discovered Building Inscription on the Temple of Denderah, $G M$ 108, 1989, 75-85. R.S. Bianchi, Images of Cleopatra VII Reconsidered, in: S. Walker \& S.-A. Ashton (edd.), Cleopatra Reassessed, The British Museum Occasional Paper 103, London 2003, 13f.

86 Quaegebeur, GM 120, 1991, 49-72.

87 PM VI 79 (257)-(260).

${ }^{88}$ Ray, in: Cleopatra Reassessed, 9. 
dekoriert worden ist und nach Mond und Myers errichtet wurde, um die Geburt Kaisar(ion)s zu feiern. ${ }^{89}$ Kleopatra VII. oder Kaisar(ion) sind dort oft separat opfernd dargestellt. Wenn sie zusammen abgebildet sind, steht Kleopatra VII. in der Regel vor ihrem Sohn, hat also vermeintlich eine machtvollere Position inne als in Dendera..$^{90}$ Allerdings scheint dies dynastisch nicht der entscheidende Faktor zu sein, sondern vielmehr die hervorgerufene Analogie zur ägyptischen Mythologie, nämlich die Assoziation der Königin mit Isis und Hathor bzw. die des königlichen Kindes mit Harsomtus bzw. Harpokrates: "Cleopatra, or her Egyptian advisors, were able to identify parallels to the Queen's life in Egyptian religion, and she, or they, went out of their way to make these parallels explicit. As often with Cleopatra, the motive for these identifications need not be purely personal, nor must it be solely political."91 Welche Gründe auch vorgelegen haben mögen, die Königin in einem Tempel vor, im anderen hinter Kaisar(ion) abzubilden, den Szenen ist anschaulich zu entnehmen, daß auch die letzte Ptolemäerkönigin nur eine Koregentin war, nicht aber eigenständig regierender Pharao, wenngleich sie die Macht de facto in Händen hielt.

\section{Resümee}

Ptolemäische Königinnen sind in verschiedenen Ritualszenen abgebildet worden. In Szenen, bei denen sie den König begleiten, stehen sie in der Regel an zweiter Stelle und führen kein spezifisches Opfer aus, sondern halten Sistrum, Blumen oder ähnliches in ihren Händen. Dies entspricht den altägyptischen Vorgängerinnen, auch hinsichtlich der ikonographischen Wiedergabe des Kopfschmuckes.

In der späten Ptolemäerzeit, als die Königinnen an Macht gewonnen hatten, konnten sie ihre Passivität in Ritualszenen ablegen und auch allein und sogar mit spezifischen Opferhandlungen dargestellt werden. Königin Nefertari, die Frau Ramses' II., kann dafür als eine Vorläuferin gewertet werden. Diese hatte sicherlich auch eine Ausnahmestellung inne, genau wie die späteren Ptolemäerinnen. Wie Nefertari wurden alle Ptolemäerinnen entweder direkt in der Szene oder aber im direkten Umfeld stets von einem König ergänzt, wenn auch manchmal namenlos oder räumlich getrennt. Sie sind daher in den Tempelreliefs deutlich als Koregentinnen gekennzeichnet, die durchaus als weiblicher Horus oder mit dem $n s ́ w t$-bjtj-Titel bezeichnet wurden, aber stets ein männliches Pendant neben sich hatten. Der König hatte zumindest nominell die Macht inne: Dies trug der Tradition Rechnung, daß ein Mann Pharao war, nicht eine Frau. Die Ptole-

${ }^{89}$ R. Mond \& O.H. Myers, Temples of Armant. A Preliminary Survey, London (EES) 1940, 5, 8f. Für das Mammisi von Armant ist man fast ganz auf Berichte aus dem 19. Jh. angewiesen, denn der Tempel wurde 1861/62 fast vollständig abgetragen und zum Aufbau einer Zuckerfabrik verwendet. LD IV 59c, 60-65. S. auch E. Otto, Topographie des thebanischen Gaues, UGAÄ 16, 1952, 89. D. Arnold, Temples of the Last Pharaohs, New York \& Oxford, 1999, 221-224 (mit Rekonstruktion); Ray, in: Cleopatra Reassessed, $10 \mathrm{f}$.

${ }^{90}$ Murnane, Ancient Egyptian Coregencies. 102, fig. 8, zur Verteilung der Darstellungen und Kartuschen von Kleopatra VII. und Kaisarion nach PM V 153-157.

${ }^{91}$ Ray, in: Cleopatra Reassessed, 11. 
mäerinnen haben sich letztendlich nicht aus der Rolle der Königsgemahlin oder Koregentin lösen können - anders als Hatschepsut in der 18. Dyn. Jedoch hatten die Ptolemäerinnen mehr Macht inne als die durchschnittliche Königsgemahlin des Alten Ägypten. Dafür spricht auch, daß sie seit Berenike II. in Szenen der Herrschaftsübergabe als Koregentinnen dargestellt wurden.

Für die Verehrung der nach ihrem Tode vergöttlichten Arsinoe II. durch Ptolemaios II. können Tetisheri und Ahmes-Nefertari aus der 18. Dyn. sowie Nefertari aus der 19. Dyn. als Vorläuferinnen gewertet werden. Sie stellten ihrerseits genauso Ausnahmen dar wie später Arsinoe II. unter den Ptolemäerinnen.

Unter Kleopatra III. wurde die Stellung der Mutter zweier aufeinanderfolgender Könige (Ptolemaios IX. und X.) markant hervorgehoben. Schon seit dem AR wurden Königsmütter zusammen mit dem Herrscher dargestellt, wie weiter oben anhand der Beispiele von Iput, Mutter Pepis I., und Tuja, Mutter Ramses' II., demonstriert, so daß man auf altägyptische Vorbilder zurückgreifen konnte. Kleopatra III. wurde jedoch weitaus exzessiver eingebunden, so daß auch in den Tempelreliefs deutlich wird, daß ihre Machtposition unvergleichlich größer gewesen sein muß als die ihrer altägyptischen Vorgängerinnen.

Zusammenfassend ist festzuhalten, daß die Ptolemäer bei der Darstellung von Königinnen auf die Traditionen des Alten Ägypten wohl zurückgriffen, sie aber auch kontinuierlich nach eigenen dynastischen Bedürfnissen modifiziert haben. Dabei wurde der erreichte status quo in der Machtposition einer Königin nicht immer ikonographisch beibehalten, sondern je nach politischer Lage auch wieder zurückgenommen, wie man an Kleopatra VI. Tryphaina erkennen kann. Dieses Phänomen liegt größtenteils im Legitimationswillen der Ptolemäer begründet. Zum einen mußte die Herrschaftsabfolge betont werden, zum anderen mußten die einzelnen Machtkonstellationen wiedergegeben werden. Dies stellte gewisse Anforderungen an die Konzeption von Reliefszenen, wie z.B. die Abbildung der einen Gattin auf der einen Wand, die der anderen auf der entsprechenden anderen Wand, wie wir bei Kleopatra II. und III gesehen haben. Die Darstellung zweier Königinnen an sich ist keine Einführung der Ptolemäerzeit, wie die Stele aus der Zeit Thutmosis' II. mit Ahmes und Hatschepsut zeigt (Abb. 3).

Die Streitigkeiten und Bedürfnisse der makedonisch-stämmigen Dynastie konnten unter Heranziehung traditioneller Darstellungsmittel in die ägyptischen Tempel übertragen werden, wenngleich die Ratlosigkeit in manchen Fällen offensichtlich wird: Nicht umsonst steht Kleopatra III. in etlichen Fällen hinter einem 'namenlosen' Ptolemäer. Somit erweitern nicht nur hieroglyphische, griechische und demotische Inschriften unser Wissen über die machtpolitischen Konstellationen der Ptolemäerzeit, sondern auch die Darstellungen der Königinnen in den ägyptischen Tempeln, die uns subtile Details liefern. Sie müssen wie die Inschriften 'gelesen' und 'entziffert' werden. 


\section{Bibliographie}

Albersmeier, Untersuchungen zu den Frauenstatuen $=\mathrm{S}$. Albersmeier, Untersuchungen zu den Frauenstatuen des Ptolemäischen Ägypten, AegTrev 10, 2002.

Albersmeier \& Minas, Weihrelief = S. Albersmeier \& M. Minas, Ein Weihrelief für die vergöttlichte Arsinoe II. Philadelphos, in: Egyptian Religion - The Last Thousand Years. Studies Dedicated to the Memory of Jan Quaegebeur (edd. W. Clarysse et al.), OLA 84.

De Morgan, Kom Ombo I-II = J. de Morgan, Catalogue des monuments et inscriptions de l'Égypte antique, Série 1, Haute Egypte, II. Kom Ombos I, Wien 1895, III. Kom Ombos II, Wien 1902.

Derchain, El Kab I = Ph. Derchain, El Kab I. Les monuments religieux à l'entrée de l'ouady Hellal, Bruxelles 1971.

Desroches-Noblecourt \& Kuentz, Le petit temple d'Abou Simbel = Chr. DesrochesNoblecourt \& Ch. Kuentz, Le petit temple d'Abou Simbel: "Nofretari pour qui se lève le dieu-soleil" I-II, Le Caire 1968.

Devauchelle, $R d E 40,1989$ = D. Devauchelle, Brèves communications: notes ptolémaïques, § 3, RdE 40, 1989, 190.

Du Bourguet, Le temple de Deir al-Médîneh $=\mathrm{P}$. du Bourguet, Le temple de Deir alMédîneh, MIFAO 121, Le Caire 2002.

Edfou = É. Chassinat, Le Temple d'Edfou I (1897)-VIII (1933): Text; IX (1929)-XIV (1934): Tafeln; S. Cauville \& D. Devauchelle, I-II (1984-1990), XV (1985).

Gauthier, LdR IV = H. Gauthier, Le Livre de Rois d'Égypte IV. De la XXVe Dynastie à la fin des Ptolémées, MIFAO 20, Le Caire 1916.

Heinen, Der Sohn des 6. Ptolemäers $=$ H. Heinen, Der Sohn des 6. Ptolemäers im Sommer 145. Zur Frage nach Ptolemaios VII. Neos Philopator und zur Zählung der Ptolemäerkönige, in: Akten des 21. Int. Papyrologenkongresses, Berlin, 13.-19. 8.1995 (edd. B. Kramer et al.), APF Beiheft 3, Stuttgart \& Leipzig 1997, 449-460.

Hölbl, Geschichte = G. Hölbl, Geschichte des Ptolemäerreiches. Politik, Ideologie und religiöse Kultur von Alexander dem Großen bis zur römischen Eroberung, Darmstadt 1994.

Hölbl, Weiblicher Pharao = G. Hölbì, Ptolemäische Königin und weiblicher Pharao, in: Faraoni come dei, Tolemei come faraoni. Atti del V Congresso Internazionale Italo-Egiziano, Torino, Archivo di Stato, 8-12 dicembre 2001 (edd. N. Bonacasa et al.), Torino/Palermo 2003, 88-97.

$\mathrm{Huß,} \mathrm{Ägypten} \mathrm{in} \mathrm{hellenistischer} \mathrm{Zeit} \mathrm{=} \mathrm{W.} \mathrm{Huß,} \mathrm{Ägypten} \mathrm{in} \mathrm{hellenistischer} \mathrm{Zeit,} \mathrm{332-30}$ v. Chr., München 2001.

L $D=\mathrm{R}$. Lepsius, Denkmäler aus Ägypten und Äthiopien, Abt. I-VI, Berlin 1849-1859.

Minas, Hieroglyphische Ahnenreihen = M. Minas Die hieroglyphischen Ahnenreihen der ptolemäischen Könige. Ein Vergleich mit den Titeln der eponymen Priester in den griechischen und demotischen Papyri, AegTrev 9, Trier 2000.

Minas, Dekorationstätigkeit $=$ M. Minas, Die Dekorationstätigkeit von Ptolemaios VI. Philometor und Ptolemaios VIII. Euergetes II. an altägyptischen Tempeln, 1. Teil, OLP 27, 1996, 51-78; 2. Teil, OLP 28, 1997, 87-121.

Murnane, Ancient Egyptian Coregencies = J. Murnane, Ancient Egyptian Coregencies, SAOC 40, Chicago 1977.

Pestman, Chronologie = P.W. Pestman, Chronologie égyptienne d'après les textes démotiques (332 av. J.-C.-453 ap. J.-C.). P.L. Bat. 15, Leiden 1967.

Philae I = H. Junker, Der große Pylon des Tempels der Isis in Philä, Österreichische Akademie der Wissenschaften, Phil.-hist. Kl., Denkschriften, Sonderband, Wien 1958. 
Quaegebeur, Reines ptolémaïques = J. Quaegebeur, Reines ptolémaïques et traditions égyptiennes, in: Das ptolemäische Ägypten. Akten des Internationalen Symposions, 27.-29. September 1976 in Berlin (edd. H. Maehler \& V.M. Strocka), Mainz 1978, 245-262.

Quaegebeur, BIFAO 69, 1971 = J. Quaegebeur, Ptolémée II en adoration devant Arsinoé II divinisée, BIFAO 69, 1971, 191-217.

Quaegebeur, JNES 30, 1971 = J. Quaegebeur, Documents Concerning a Cult of Arsinoe Philadelphos at Memphis, JNES 30, 1971, 239-270.

Quaegebeur, GM 87, 1985 = J. Quaegebeur, Arsinoé Philadelphe, reine, "roi" et déesse, à Hildesheim, GM 87, 1985, 73-78.

Quaegebeur, Documents égyptiens anciens = J. Quaegebeur, Documents égyptiens anciens et nouveaux relatifs à Arsinoé Philadelphe, in: Le culte du souverain dans l'Égypte ptolémaïque au IIIe siècle avant notre ère. Actes du colloque international, Bruxelles 10 Mai 1995, Stud. Hell. 34, Leuven 1998, 73-108.

Quaegebeur, Une scène historique méconnue = J. Quaegebeur, Une scène historique méconnue au grand temple d'Edfou, in: Egitto e storia antica dall'ellenismo all'età araba. Bilancio di un confronto, Atti del colloquio internazionale, Bologna, 31 Agosto-2 Settembre 1987 (edd. L. Criscuolo \& G. Geraci), Bologna 1989, 595 -608 .

Ray, in: Cleopatra Reassessed = J. Ray, Cleopatra in the Temples of Upper Egypt: The Evidence of Dendera and Armant, in: S. Walker \& S.-A. Ashton (edd.), Cleopatra Reassessed, The British Museum Occasional Paper 103, London 2003.

Robins, Wepwawet, $1986=$ G. Robins, The Role of the Royal Family in the 18th Dynasty up to the End of the Reign of Amenhotep III: 1. Queens, in: Wepwawet 2, Papers in Egyptology, Summer 1986, 10-14.

Robins, Women = G. Robins, Women $\cdot$ in Ancient Egypt, Cambridge/Massachusetts (Harvard University) 1993.

Troy, Patterns of Queenship = L. Troy, Patterns of Queenship in Ancient Egyptian Myth and History, Boreas: Uppsala Studies in Ancient Mediterranean and Near Eastern Civilizations 14, Uppsala 1986.

Winter, Herrscherkult $=$ E. Winter, Der Herrscherkult in den ägyptischen Ptolemäertempeln, in: Das ptolemäische Ägypten. Akten des internationalen Symposions, 27.-29. September 1976 in Berlin (edd. H. Maehler \& V.M. Strocka), Mainz 1978, $147-160$. 